\title{
Structure of the Polymer Backbones in PolyMOF Materials
}

Paulo G.M. Mileo ${ }^{1}$, Shichen Yuan², Sergio Ayala Jr. ${ }^{3}$, Pu Duan², Rocio Seminoํ, Seth M. Cohen ${ }^{3 *}$, Klaus Schmidt-Rohr ${ }^{2 *}$ and Guillaume Maurin ${ }^{1 *}$

\section{SUPPORTING INFORMATION}

\author{
${ }^{1}$ ICGM, Univ. Montpellier, CNRS, ENSCM, Montpellier, France \\ ${ }^{2}$ Department of Chemistry, Brandeis University, Waltham, MA 02453, USA \\ ${ }^{3}$ Department of Chemistry and Biochemistry, University of California, San Diego, La \\ Jolla, CA 92093, USA
}




\section{DFT calculations and analysis}

All DFT calculations were performed using the CP2K code. ${ }^{1}$ The triple- $\zeta$ valence plus two polarization (TZV2P) basis set ${ }^{2}$ was used for $\mathrm{H}, \mathrm{O}$, and $\mathrm{C}$ atoms, while $\mathrm{Zr}$ atoms were treated using the double- $\zeta$ valence plus polarization (DZVP) basis set. $^{3}$ The pseudopotentials applied to all atoms were those derived by Goedecker, Teter, and Hutter. ${ }^{4}$ A relative cutoff of 500 Ry and a convergence criterion for the self-consistent field interactions of $10^{-6}$ were employed. Semi-empirical dispersion corrections as implemented in the DFT-D3 method were considered. ${ }^{5}$

\section{NMR Details}

Solid-state NMR (ssNMR). Solid-state NMR experiments were performed on a Bruker Avance Neo 400WB NMR spectrometer at ${ }^{1} \mathrm{H}$ and ${ }^{13} \mathrm{C}$ resonance frequencies of $400 \mathrm{MHz}$ and $100 \mathrm{MHz}$, respectively. Most of the measurements were conducted using a Bruker double-resonance magic-angle-spinning (MAS) probe with 4-mm zirconia rotors. Samples were directly loaded into the rotors as received. The $90^{\circ}$ pulse length for ${ }^{1} \mathrm{H}$ and ${ }^{13} \mathrm{C}$ were $3.6 \mathrm{~ms}$ and $4.0 \mathrm{~ms}$, respectively. Two-pulse phase modulation (TPPM) ${ }^{6}{ }^{1} \mathrm{H}-$ decoupling at a field strength of $\gamma B_{1} / 2 \pi=95 \mathrm{kHz}$ was used for ${ }^{1} \mathrm{H}$ dipolar decoupling during the Hahn echo ${ }^{7}$ or total suppression of sidebands (TOSS) ${ }^{8}$ for dead-time-free detection, while decoupling by SPINAL- $64{ }^{9}$ at $\gamma B_{1} / 2 \pi=85 \mathrm{kHz}$ was used during signal acquisition. ${ }^{13} \mathrm{C}$ chemical shifts were referenced externally to TMS via the carboxyl resonance of $\alpha-1-$ ${ }^{13} \mathrm{C}$-glycine at $176.49 \mathrm{ppm}$ as a secondary reference. ${ }^{1} \mathrm{H}$ chemical shifts were externally 
referenced to hydroxyapatite at $0.18 \mathrm{ppm}$. All NMR experiments were conducted at approximately $300 \mathrm{~K}$.

An acquisition time between 6.2 and $15.5 \mathrm{~ms}$ was typically used for the $1 \mathrm{D}{ }^{13} \mathrm{C}$ NMR experiments, except with poly( $\varepsilon$-caprolactone), a semicrystalline reference polymer which required $21.9 \mathrm{~ms}$ due to sharp peaks. The ${ }^{13} \mathrm{C} B_{1}$ field strength used in cross-polarization was optimized for each MAS frequency. Quantitative composite-pulse multiCP ${ }^{10}{ }^{13} \mathrm{C}$ NMR spectra were all acquired at $14 \mathrm{kHz}$ MAS for all the samples. For comprehensive polarization, at least five $1.1 \mathrm{~ms} \mathrm{CP}$ blocks separated by four ${ }^{1} \mathrm{H}$ repolarization periods of two times ${ }^{1} \mathrm{H} T_{1}$ relaxation times each were used. The spectra presented were typically signal averaged for 1 to 8 hours with the recycle delay varying between $0.8 \mathrm{~s}$ and $3.2 \mathrm{~s}$.

Heteronuclear Correlation (HetCor). Two-dimensional ${ }^{1} \mathrm{H}-{ }^{13} \mathrm{C}$ heteronuclear correlation (HetCor) ${ }^{11}$ spectra were measured at a $7.5 \mathrm{kHz}$ MAS frequency with frequency-switched Lee-Goldburg homonuclear ${ }^{1} \mathrm{H}$ decoupling, ${ }^{12} 0.4 \mathrm{~ms}$ of HartmannHahn cross-polarization with a 90-100\% amplitude ramp on the ${ }^{1} \mathrm{H}$ channel, and TOSS before detection. The recycle delays ranged between 0.8 and $1.5 \mathrm{~s}$, depending on the $T_{1 \mathrm{H}}$ relaxation time of the sample. A typical spectrum was averaged between 22-27 $\mathrm{h}$. The chemical shift of ${ }^{1} \mathrm{H}$ associated with the phenyl ether linkage were revealed by ${ }^{1} \mathrm{H}$ cross sections taken at $\sim 70 \mathrm{ppm}\left(\mathrm{OCH}_{2}\right){ }^{13} \mathrm{C}$ chemical shifts.

1H wide-line separation (WISE). For characterizing segmental mobilities, ${ }^{1} \mathrm{H}$ wide-line separation (WISE) experiments ${ }^{13}$ were performed at MAS frequency of $5 \mathrm{kHz}$, with dipolar decoupling at $\gamma B_{1} / 2 \pi=55 \mathrm{kHz}$ on the ${ }^{13} \mathrm{C}$ channel. A short contact time of $0.08 \mathrm{~ms}$ 
was used to avoid intersegmental cross-polarization. The relaxation delays ranged from 1.4-s to 4-s, and a typical experiment was conducted over 18 to $38 \mathrm{~h}$ of signal averaging.

Chemical-shift-anisotropy (CSA) dephasing. For characterizing the magnitude of the CSA of rigid segments, 5-pulse CSA dephasing experiments were conducted at $5 \mathrm{kHz}$ MAS. ${ }^{14}$ The ${ }^{13} \mathrm{C}$ CSA filter was combined with an incrementation of the preceding zperiod in four steps of $t_{r} / 4$, which provides the " $\gamma$-integral" to suppress the sidebands up to the fourth order. Contact times were $1.1 \mathrm{~ms}$. With the recycle delays ranging from 1.4 to $5 \mathrm{~s}$ depending on the $T_{1 \mathrm{H}}$ of the specific samples, 112 to 1344 transients were collected over 7 to $18 \mathrm{~h}$.

${ }^{1} \mathrm{H}$ with 2-ms $T_{1 \rho}$ filter at MAS frequency of $14 \mathrm{kHZ}$. The signal for the mobile water and the formate molecules can be suppressed by a 2 -ms $T_{1 \rho}$ filter with a spin-locking field of $\gamma B_{1} / 2 \pi=78 \mathrm{kHz}$ at the MAS frequency of $14 \mathrm{kHz}$. The recycle delay varied between 2 to $4 \mathrm{~s}$ depending on the $T_{1 \mathrm{H}}$ of the sample.

$T_{1 \mathrm{C}}$ filtered CP. The 3-ms and 5-s $T_{1 \mathrm{C}}$-filtered spectra were acquired at MAS frequency of $14 \mathrm{kHz}$ for all pbdc and polyUiO66 samples. The number of scans for all the samples varied from 512 to 2560 , with total experimental time ranges from 0.5 to $8 \mathrm{~h}$.

${ }^{1} \mathrm{H}$ inversion recovery. ${ }^{1} \mathrm{H}$ inversion recovery ${ }^{15}$ experiments were applied at $14 \mathrm{kHz}$ to magnify potential differences between the ${ }^{1} \mathrm{H}$ spin-lattice relaxation time $T_{1 \mathrm{H}}$ of sharp spectral components in polyUiO66-6a, with 65,532 scans accumulated for $18.6 \mathrm{~h}$ near the zero-crossing time of $0.2 \mathrm{~ms}$ due to the weak signal. 


\section{Synthesis and Characterization Details}

General materials and methods. Starting materials were purchased and used from commercially available suppliers (Sigma-Aldrich, Acros Organics, Matrix Scientific, and others) without further purification. ${ }^{1} \mathrm{H}$ nuclear magnetic resonance (NMR) spectra of digested samples were collected using a Varian spectrometer running at $400 \mathrm{MHz}$.

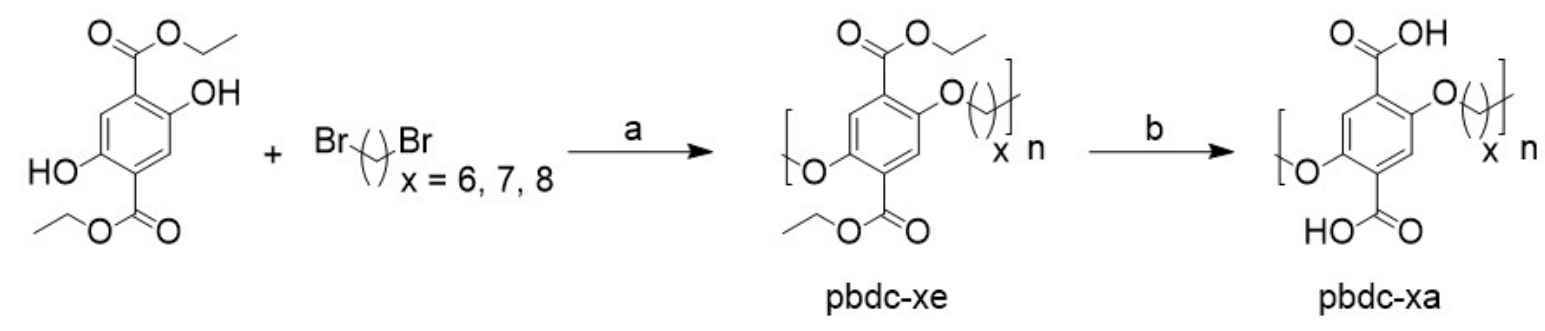<smiles>[Y]C(C)(C)Oc1cc(C(=O)O)c(O[Ga]C)cc1C(=O)O</smiles>

pbdc-xa<smiles>[Y]C(C)(C)Oc1cc(C(=O)O)c(O[Ga]C)cc1C(=O)O</smiles>

pbdc-xa

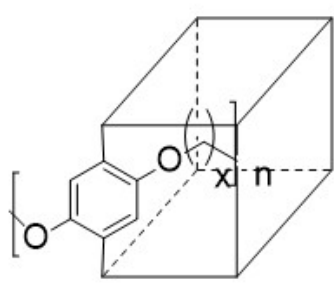

polyIRMOF-1-xa

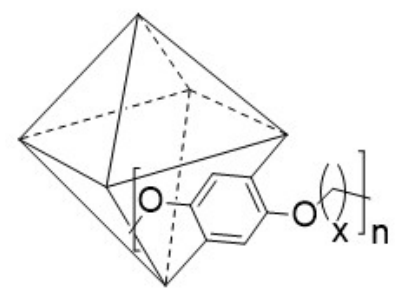

polyUiO-66-xa

Scheme S1. General procedure for synthesis of polyMOFs using polymer ligands pbdc$x a$ is presented. Reagents and conditions: a) $\mathrm{K}_{2} \mathrm{CO}_{3}, \mathrm{DMF}, 10{ }^{\circ} \mathrm{C}, 24 \mathrm{~h}$; b) $\mathrm{NaOH}, 1: 1$ THF/ $\mathrm{H}_{2} \mathrm{O}$, r.t., overnight; c) $\mathrm{Zn}\left(\mathrm{NO}_{3}\right)_{2} \cdot 6 \mathrm{H}_{2} \mathrm{O}$, DMF, $100{ }^{\circ} \mathrm{C}, 24 \mathrm{~h}$; d) $\mathrm{ZrCl}_{4}, 1: 1 \mathrm{DEF} /$ formic acid, $135^{\circ} \mathrm{C}, 48 \mathrm{~h}$. 
General procedure for pbdc-xe (ester ligand). Synthesis was adapted from a previously published procedure (Zhang et al., Angew. Chem. Int. Ed., 2015, 54, 61526157). To a $100 \mathrm{~mL}$ round-bottom flask was added diethyl 2,5-dihydroxyterephthalate $(1.20 \mathrm{~g}, 4.70 \mathrm{mmol}, 1 \mathrm{eq})$, the desired dibromoalkane (4.70 mmol, $1 \mathrm{eq}), \mathrm{K}_{2} \mathrm{CO}_{3}(2.6 \mathrm{~g}$, $19 \mathrm{mmol}, 4.0 \mathrm{eq}$ ), and $20 \mathrm{~mL}$ of DMF. The reaction was stirred at $100^{\circ} \mathrm{C}$ for $24 \mathrm{~h}$. Then, the reaction mixture was poured into a centrifuge tube containing water $(40 \mathrm{~mL})$, followed by washes with methanol $(3 \times 50 \mathrm{~mL})$. The polymers were dried in a vacuum oven at 40 ${ }^{\circ} \mathrm{C}$.

pbdc-6e: Yield: 46\% (796 mg, $4.70 \mathrm{mmol}) .{ }^{1} \mathrm{H} \mathrm{NMR}\left(400 \mathrm{MHz}, \mathrm{CDCl}_{3}\right) \delta 7.33(\mathrm{~s}, 2 \mathrm{H})$, $4.35(\mathrm{q}, J=7.1 \mathrm{~Hz}, 4 \mathrm{H}), 4.01(\mathrm{t}, J=6.3 \mathrm{~Hz}, 4 \mathrm{H}), 1.83(\mathrm{~s}, 4 \mathrm{H}), 1.55(\mathrm{~s}, 4 \mathrm{H}), 1.37(\mathrm{t}, J=7.1$ $\mathrm{Hz}, 7 \mathrm{H}) . M_{n}: 4440 \mathrm{~g} / \mathrm{mol} . M_{w} / M_{n}: 1.80$

pbdc-7e: Yield: 44\% (750 mg, $2.05 \mathrm{mmol}) .{ }^{1} \mathrm{H}$ NMR $\left(400 \mathrm{MHz}, \mathrm{CDCl}_{3}\right) \delta 7.34(\mathrm{~s}, 2 \mathrm{H})$, $4.36(\mathrm{q}, J=7.1 \mathrm{~Hz}, 4 \mathrm{H}), 4.00(\mathrm{t}, J=6.4 \mathrm{~Hz}, 4 \mathrm{H}), 1.93-1.68(\mathrm{~m}, 4 \mathrm{H}), 1.50(\mathrm{~d}, J=7.0 \mathrm{~Hz}$, 4H), $1.45-1.27(\mathrm{~m}, 9 \mathrm{H}) . \mathrm{Mn}: 4240 \mathrm{~g} / \mathrm{mol} . M_{w} / M_{n}: 1.46$

pbdc-8e: Yield: $30 \%$ (508 mg, $1.39 \mathrm{mmol}) .{ }^{1} \mathrm{H}$ NMR (400 MHz, $\left.\mathrm{CDCl}_{3}\right) \delta 7.33(\mathrm{~s}, 2 \mathrm{H})$, $4.36(\mathrm{q}, J=7.1 \mathrm{~Hz}, 2 \mathrm{H}), 3.99(\mathrm{t}, J=6.3 \mathrm{~Hz}, 2 \mathrm{H}), 1.88-1.74(\mathrm{~m}, 2 \mathrm{H}), 1.48(\mathrm{~s}, 2 \mathrm{H}), 1.38$ (t, $J=7.0 \mathrm{~Hz}, 6 \mathrm{H}) . M_{n}: 4760 \mathrm{~g} / \mathrm{mol} . M_{w} / M_{n}: 1.89$

General polymer hydrolysis procedure for polymer acid ligands. The polymer ester was added to a $250 \mathrm{~mL}$ round-bottom flask, along with sodium hydroxide (15 equivalents), and placed in a 1:1 solution containing of tetrahydrofuran (THF): water. The mixture was stirred $24 \mathrm{~h}$, or until the solution became clear. The THF was reduced by evaporation. The solution was acidified to a $\mathrm{pH}$ value of $\sim 1$ using a $4 \mathrm{M} \mathrm{HCl}$ solution. The resultant solid was collected by vacuum filtration. The solid was washed with copious amounts of $4 \mathrm{M}$ 
$\mathrm{HCl}$ solution, and water to remove any salts. All samples were dried in the vacuum oven at $40{ }^{\circ} \mathrm{C}$ for $4 \mathrm{~h}$.

pbdc-6a: Yield: 89\% (520 mg, $2.0 \mathrm{mmol}) .{ }^{1} \mathrm{H}$ NMR (400 MHz, DMSO-d 6$) \delta 7.26(\mathrm{~s}, 2 \mathrm{H})$, $3.98(\mathrm{t}, J=6.0 \mathrm{~Hz}, 4 \mathrm{H}), 1.69(\mathrm{~s}, 4 \mathrm{H}), 1.56-1.25(\mathrm{~m}, 4 \mathrm{H})$.

pbdc-7a: Yield: 97\% (450 mg, $1.5 \mathrm{mmol}) .{ }^{1} \mathrm{H}$ NMR (400 MHz, DMSO-d 6 ) $\delta 7.26$ (s, 2H), $3.97(\mathrm{t}, J=5.8 \mathrm{~Hz}, 4 \mathrm{H}), 1.70(\mathrm{t}, J=17.3 \mathrm{~Hz}, 4 \mathrm{H}), 1.51-1.18(\mathrm{~m}, 8 \mathrm{H})$.

pbdc-8a: Yield: 82\% (340 mg, $1.3 \mathrm{mmol}) .{ }^{1} \mathrm{H}$ NMR (400 MHz, DMSO-d 6 ) $\delta 7.25$ (s, 2H), $3.97(\mathrm{t}, J=6.0 \mathrm{~Hz}, 2 \mathrm{H}), 1.68(\mathrm{~s}, 2 \mathrm{H}), 1.42(\mathrm{~s}, 2 \mathrm{H}), 1.29(\mathrm{~d}, J=19.1 \mathrm{~Hz}, 3 \mathrm{H})$.

General procedure for polyIRMOF-1 synthesis prepared from pbdc-xa $(x=6,7,8)$. Polymer-ligand (pbdc-xa, $0.10 \mathrm{mmol}$ of monomer repeating unit) and $\mathrm{Zn}\left(\mathrm{NO}_{3}\right)_{2} \cdot 6 \mathrm{H}_{2} \mathrm{O}$ ( $0.60 \mathrm{mmol})$ were added to $2.5 \mathrm{~mL}$ DMF in a $20 \mathrm{~mL}$ glass vial. The vial was placed in an oven at $100{ }^{\circ} \mathrm{C}$ for $24 \mathrm{~h}$. Crystals were washed with DMF immediately after removal from the oven $(3 \times 5 \mathrm{~mL})$.

Activation of $Z n-p b d c-x a$. The materials were washed by exchanging the solvent with DMF once for one $d$, then with $\mathrm{CH}_{2} \mathrm{Cl}_{2}$ once every $2 \mathrm{~h}(5 \times 5 \mathrm{~mL})$, followed by an exchange with hexane once every $2 \mathrm{~h}(3 \times 5 \mathrm{~mL})$. The materials were then dried under vacuum overnight in a $20 \mathrm{~mL}$ vial at $75^{\circ} \mathrm{C}$, and purged with $\mathrm{N}_{2}$ in a septum-capped vial for storage. For PXRD Analysis. Crystals were collected by filtration and washed with DMF $(3 \times 5 \mathrm{~mL})$. The samples were loaded into a flat PXRD holder while still wet. PXRD data were collected at ambient temperature on a Bruker D8 Advance diffractometer at $40 \mathrm{kV}$ and 40 $\mathrm{mA}$ for $\mathrm{Cu} \mathrm{Ka}(\lambda=1.5418 \AA)$, with a scan speed of $0.5 \mathrm{~s} / \mathrm{step}$, a step size of $0.02^{\circ}$ in $2 \theta$, and a $2 \theta$ range of $5-50^{\circ}$. 
${ }^{1} \mathrm{H}$ NMR Digestions. About $5 \mathrm{mg}$ of material was dissolved in $700 \mu \mathrm{L}$ DMSO-d 6 using 5 $\mu \mathrm{L}$ of $30 \%$ wt. $\mathrm{DCl}$ to digest the polyMOF.

General procedure for polyUiO-66 synthesis prepared from pbdc-xa $(x=6,7,8)$. Polymer-ligand $\left(0.03 \mathrm{mmol}\right.$ by monomer repeat unit) and zirconium(IV) chloride $\left(\mathrm{ZrCl}_{4}\right)$ (0.037 mmol) were dissolved in $20 \mathrm{~mL}$ scintillation vials using $2 \mathrm{~mL}$ of $\mathrm{N}, \mathrm{N}$ diethylformamide (DEF). After dissolving, $2 \mathrm{~mL}$ of formic acid was added to the vial. The reaction was set in a pre-heated oven at $135^{\circ} \mathrm{C}$ for $48 \mathrm{~h}$. Either powder or a brittle film was obtained at the bottom of the vial. The resultant materials were immediately washed by exchanging the solvent with copious amounts of DMF $(3 \times 10 \mathrm{~mL})$.

Activation Conditions: The materials were washed by exchanging the solvent with DMF (1×10 mL), then with $\mathrm{CH}_{2} \mathrm{Cl}_{2}(4 \times 10 \mathrm{~mL})$ for $2 \mathrm{~d}$. The materials were dried in vacuum oven at $40{ }^{\circ} \mathrm{C}$.

For PXRD Analysis. The dried samples were loaded into a flat PXRD holder. PXRD data were collected at ambient temperature as described above.

${ }^{1} \mathrm{H}$ NMR Digestions. About $5 \mathrm{mg}$ of material was dissolved in $700 \mu \mathrm{L}$ DMSO- $d_{6}$ using 5 $\mu \mathrm{L}$ of $50 \% \mathrm{wt}$. HF to digest the polyMOF. 


\section{Supporting Figures}

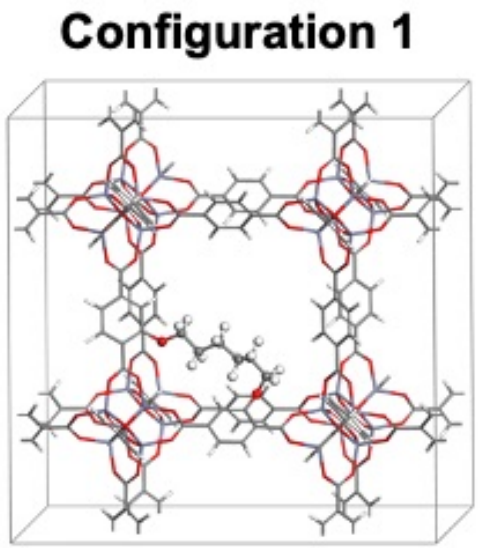

\section{Configuration 2}
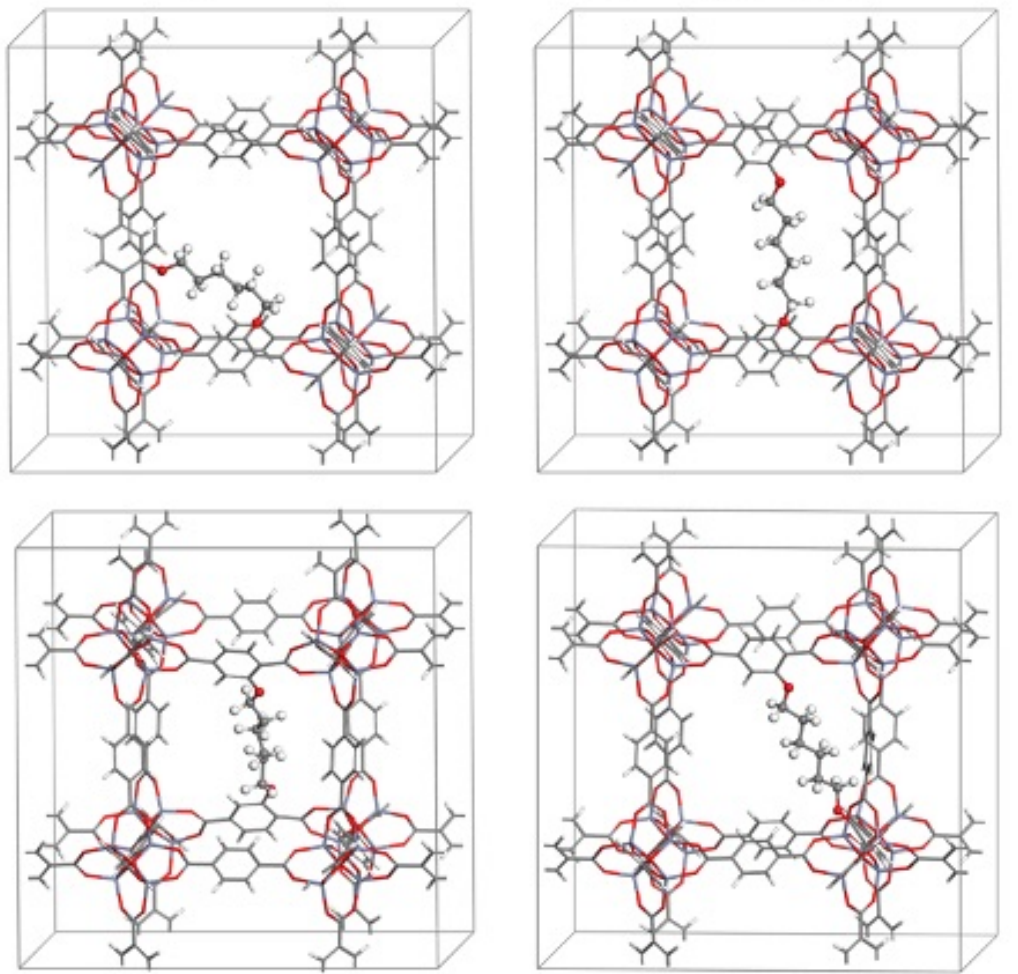

Configuration 3

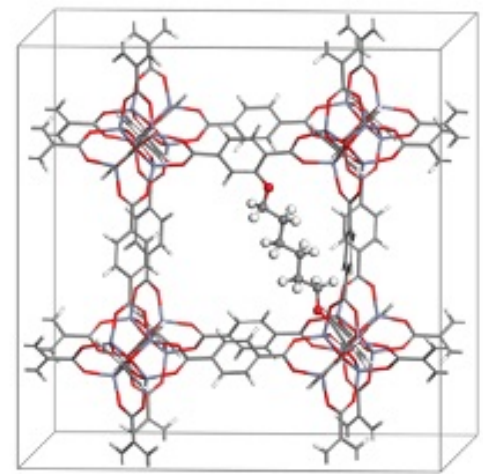

Configuration 4

Figure S1. Schemes of the four different conformations tested for the $-\left(\mathrm{CH}_{2}\right)_{x}$ - spacer in the backbone of the polymer connecting the $\mathrm{H}_{2}$ bdc linkers in polyIRMOF-1. Examples are shown for polyIRMOF-1-6a, and the spacer is highlighted by means of a ball-andstick representation. List of Configurations: Configuration 1 (top left); Configuration 2 (top right); Configuration 3 (bottom left); Configuration 4 (bottom right). Color code: $\mathrm{O}$ (red), Zn (steel blue), C (grey), H (white). 

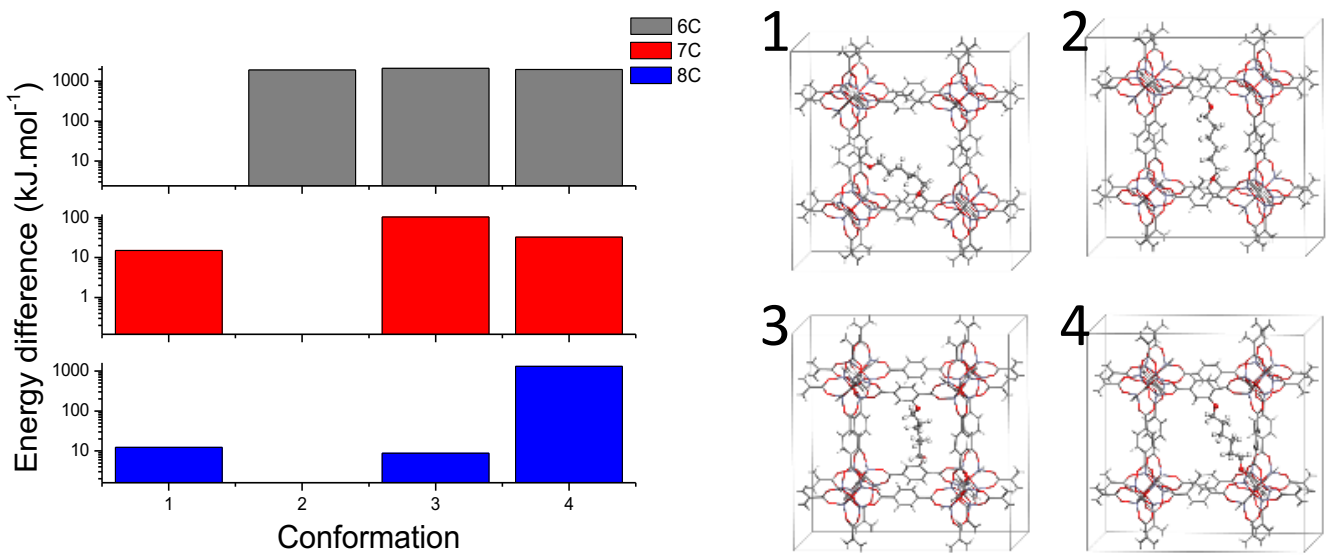

Figure S2. Energy difference in $\mathrm{kJ} \mathrm{mol}^{-1}$ of the different spacer configurations with respect to the lowest energy configuration for the single-chain polyIRMOF-1-xa (left, $x=$ 6 top, $x=7$ middle, $x=8$ bottom). On the right, a scheme of the different configurations in shown. The color code is the same as in Figure $\mathrm{S} 1$.
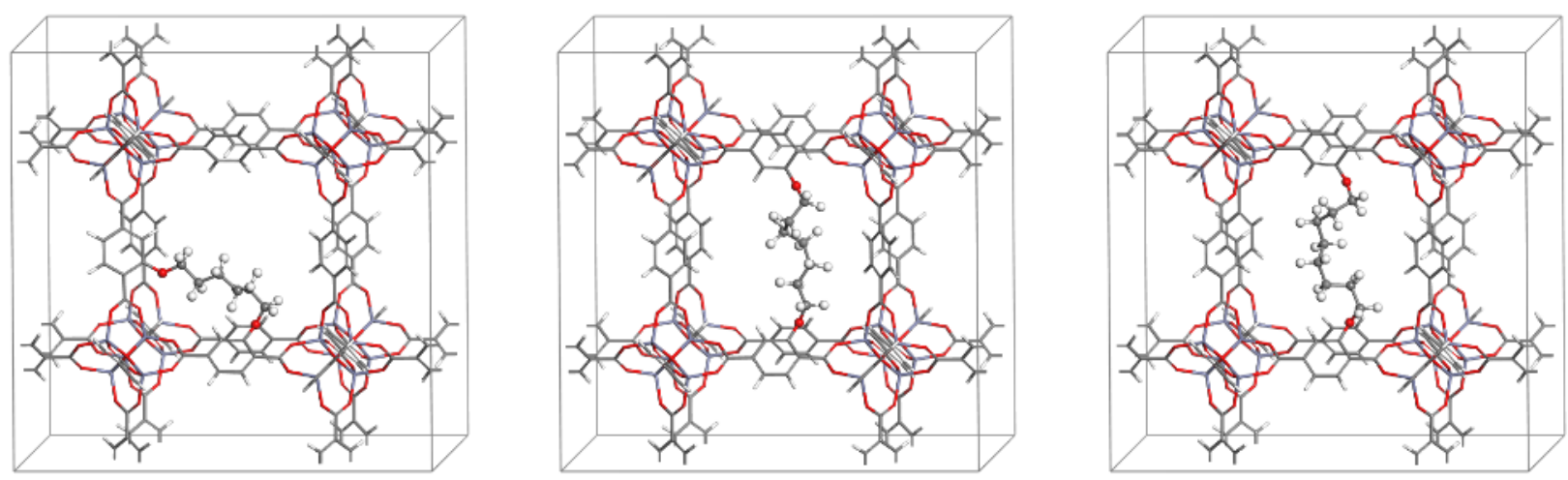

Figure S3. DFT-minimum-energy single-chain structures of polyIRMOF-1-xa incorporating $x=6,7$ and $8-\left(\mathrm{CH}_{2}\right)_{x}$ - segments in the backbone of the polymer connecting the $\mathrm{H}_{2} \mathrm{bdc}$ linkers. The color code is the same as in Figure $\mathrm{S} 1$. 
Table S1. Average C-C distances and C-C-C angles in the spacer chains for the DFTminimum-energy single-chain structures of polyIRMOF-1-xa series.

\begin{tabular}{|c|c|c|c|}
\hline & polyIRMOF-1-6a & polyIRMOF-1-7a & polyIRMOF-1-8a \\
\hline C-C distance (A) & 1.53 & 1.53 & 1.53 \\
\hline C-C-C angle ( $\left.\mathbf{~}^{\circ}\right)$ & 113 & 114 & 114.7 \\
\hline
\end{tabular}

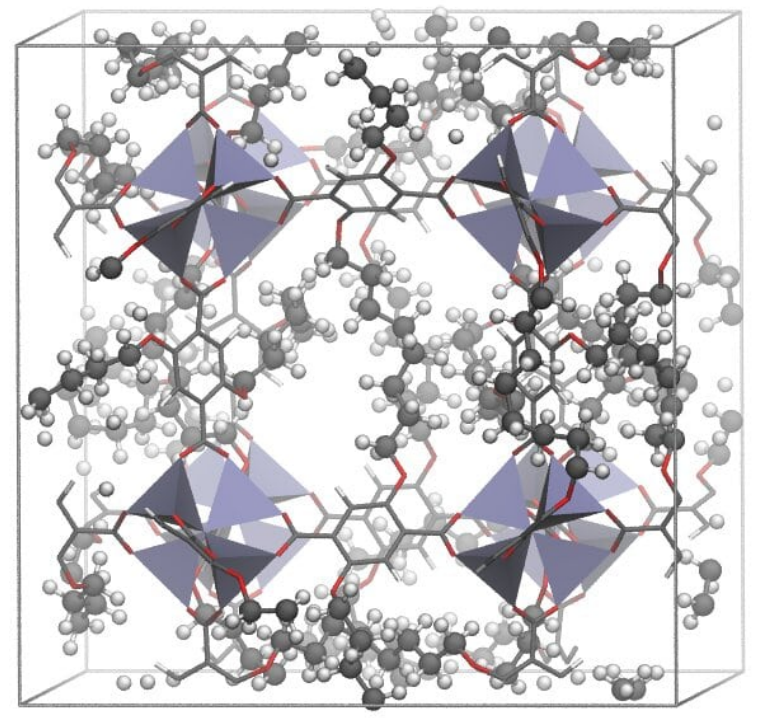

Figure S4. DFT-minimum-energy periodic polyIRMOF-1-8a structure. Color code: O (red), Zn (light blue), C (gray), H (white). 


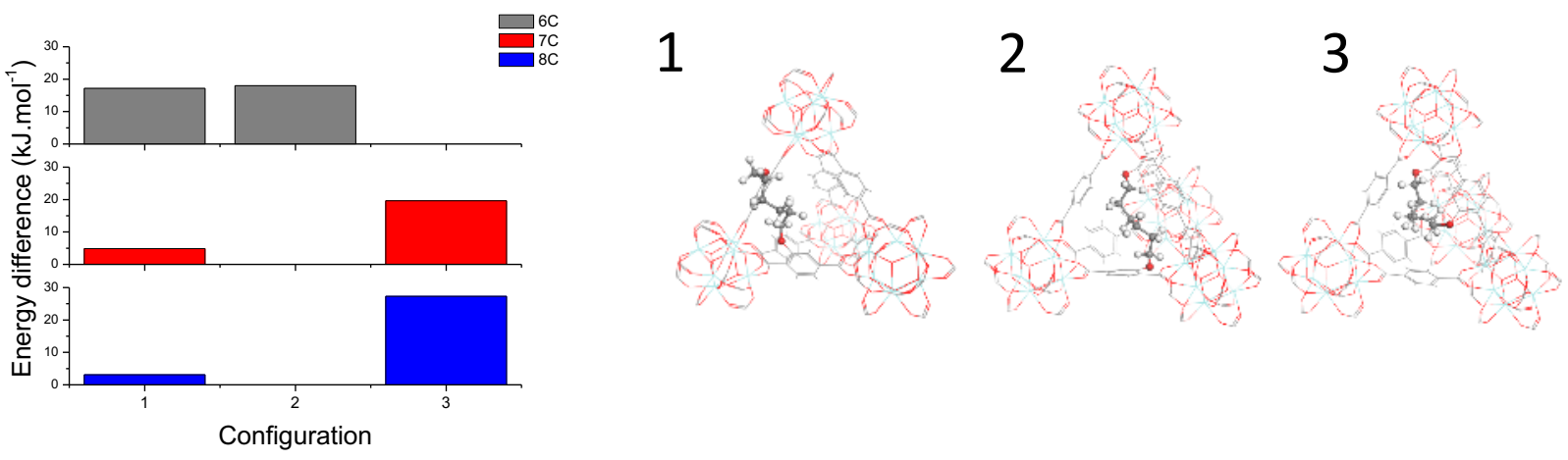

Figure S5. Energy difference (in kJ mol${ }^{-1}$ ) of the different spacer configurations with respect to the lowest energy configuration for the $T_{g}$ cages in the single-chain polyUiO66-xa (left, $x=6$ top, $x=7$ middle, $x=8$ bottom). On the right, a scheme of the different configurations is shown. Color code as in Figure S4.
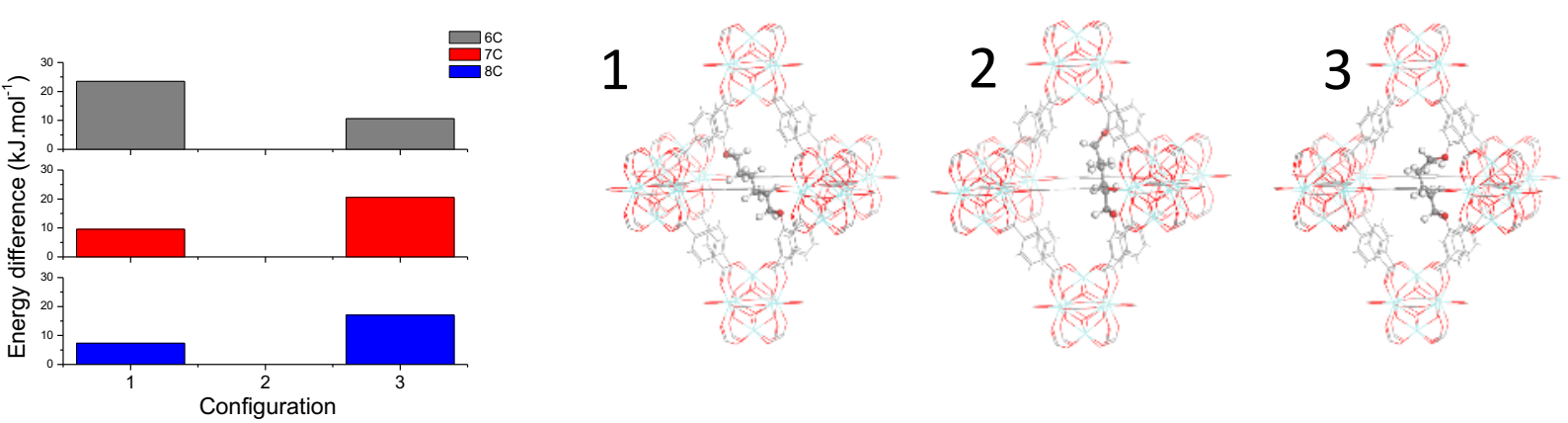

Figure S6. Energy difference (in $\mathrm{kJ} \mathrm{mol}^{-1}$ ) of the different spacer configurations with respect to the lowest energy configuration for the $\mathrm{O}_{\mathrm{h}}$ cages in the single-chain polyUiO66-xa (left, $x=6$ top, $x=7$ middle, $x=8$ bottom). On the right, a scheme of the different configurations is shown. Color code as in Figure S4. 


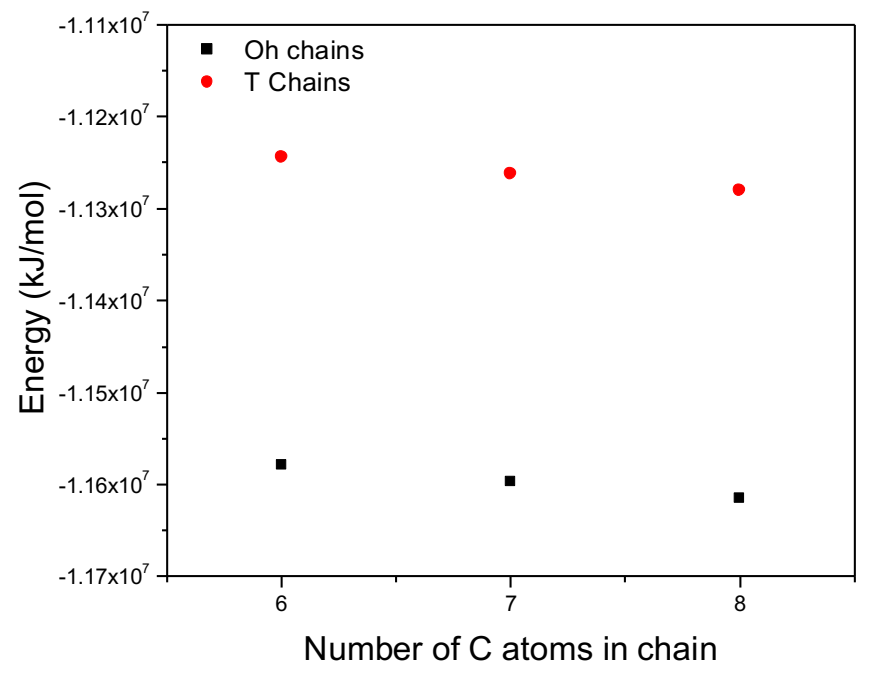

Figure S7. Energy in $\mathrm{kJ} \mathrm{mol}^{-1}$ of the different poly-UiO-66-xa systems as a function of $\mathrm{x}$. Red circles and black squares correspond to configurations where the spacer is located in tetrahedral cages and octahedral cages, respectively.
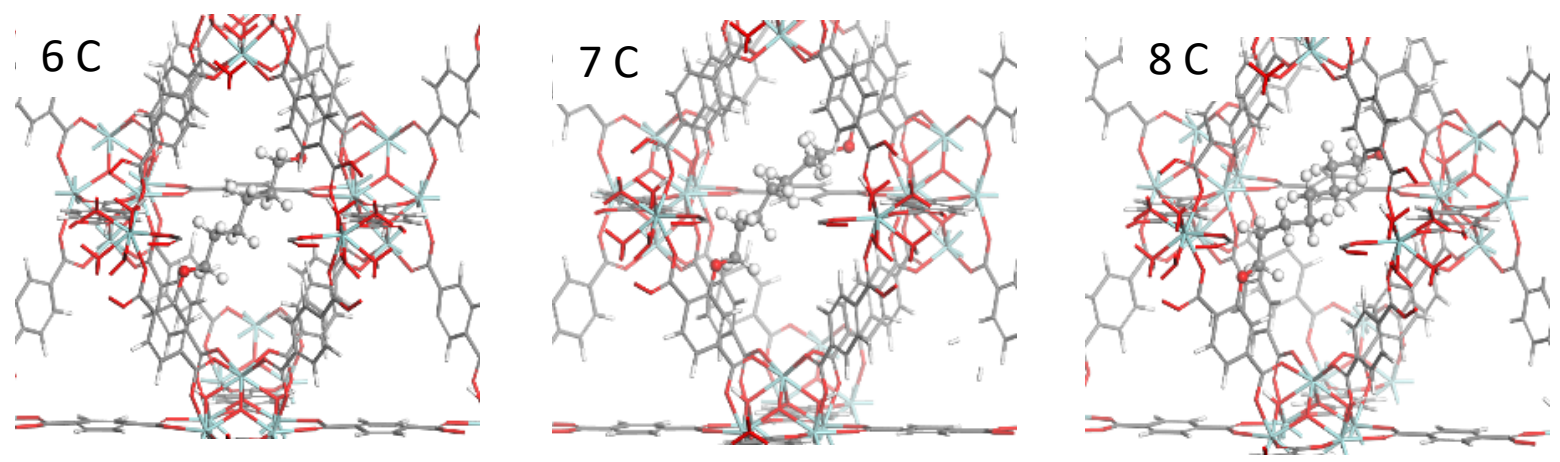

Figure S8. DFT-minimum-energy single-chain structures of polyUiO-66 incorporating $x$ $=6,7$, and $8-\left(\mathrm{CH}_{2}\right)_{x}$ - segments in the backbone of the polymer connecting the terephthalate linkers. Color code as in Figure S4. 
Table S2. Average C-C distances and $\mathrm{C}-\mathrm{C}-\mathrm{C}$ angles in the spacer chains for the DFT DFT-minimum-energy single-chain structures of polyUiO-66-xa series.

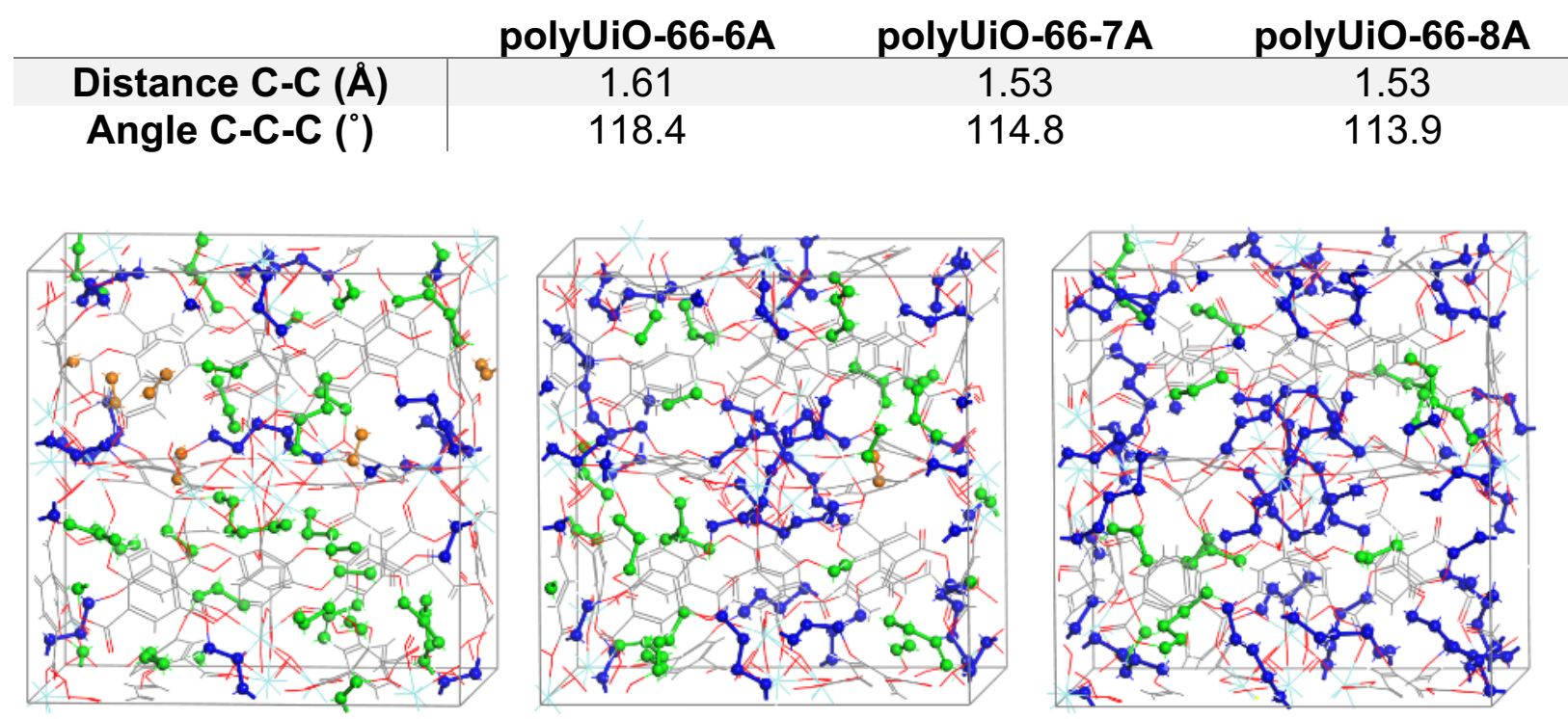

Figure S9. DFT-minimum-energy periodic structures of polyUiO-66 series for $x=6,7$ and 8. Color code as in Figure S4. Blue chains maintain their connectivity, while green and orange chains do not.

Table S3. Unit cell parameters obtained from a cell relaxation of the typical structures polyIRMOF-1-7a and polyUiO-66-7a, respectively, compared to ones observed in the canonical structures IRMOF-1 and UiO-66.

\begin{tabular}{|c|c|c|c|c|}
\hline $\begin{array}{c}\text { Cell } \\
\text { parameters }\end{array}$ & IRMOF-1 & polyIRMOF-1-6a & polyIRMOF-1-7a & polyIRMOF-1-8a \\
\hline $\mathbf{a}$ & 25.83 & 26.08 & 26.08 & 26.11 \\
\hline $\mathbf{b}$ & 25.83 & 26.05 & 26.04 & 26.12 \\
\hline $\mathbf{C}$ & 25.83 & 26.19 & 25.99 & 26.11 \\
\hline $\boldsymbol{\alpha}$ & 90.00 & 89.98 & 90.38 & 90.83 \\
\hline $\boldsymbol{\beta}$ & 90.00 & 90.24 & 90.71 & 90.02 \\
\hline Y & 90.00 & 90.35 & 90.25 & 89.83 \\
\hline
\end{tabular}


Table S4. Calculated $\mathrm{N}_{2}$ accessible surface area and free pore volume for the DFTpredicted most stable polyIRMOF-1-xa structural models. These calculations were performed using a standard geometric method (Dassault Systèmes BIOVIA, San Diego: Dassault Systèmes, 2020) with a probe molecule of $3.68 \AA$ and $0 \AA$ for the $\mathrm{N}_{2}$-accessible surface and free pore volume assessment, respectively.

\begin{tabular}{|c|c|c|}
\hline & $\begin{array}{c}\mathbf{N}_{2} \text { accessible surface area } \\
\left(\mathbf{m}^{\mathbf{2}} \mathbf{~ g}^{-\mathbf{1}}\right)\end{array}$ & $\begin{array}{c}\text { Free pore volume } \\
\left(\mathbf{c m}^{\mathbf{3}} \mathbf{~ g}^{-1}\right)\end{array}$ \\
\hline IRMOF-1 & 3770 & 1.357 \\
\hline polyIRMOF-1-6a & 2160 & 0.776 \\
\hline polyIRMOF-1-7a & 1760 & 0.708 \\
\hline polyIRMOF-1-8a & 1550 & 0.658 \\
\hline
\end{tabular}




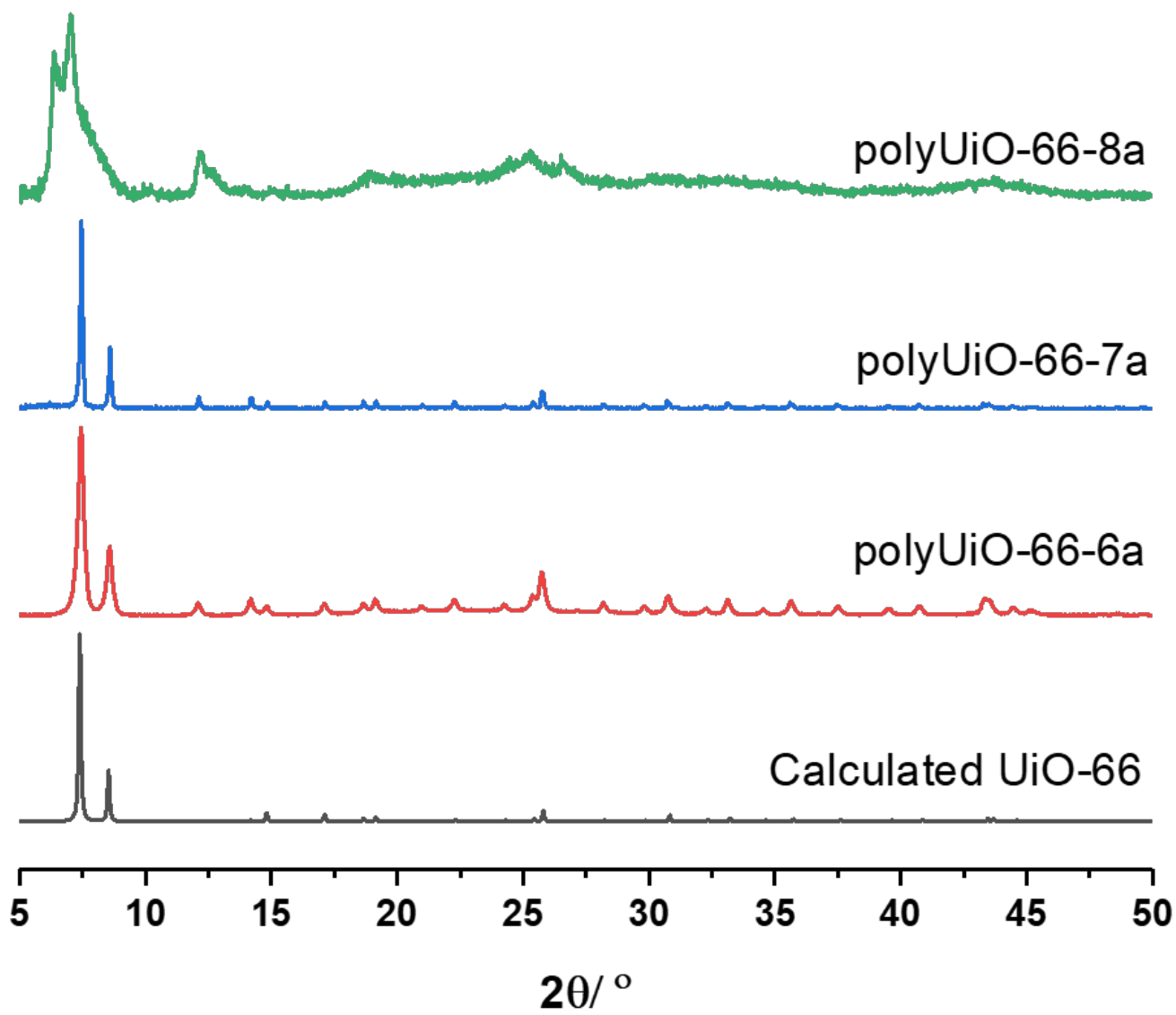

Figure S10. PXRD data obtained for polyUiO-66-xa prepared from pbdc-xa ligands. 

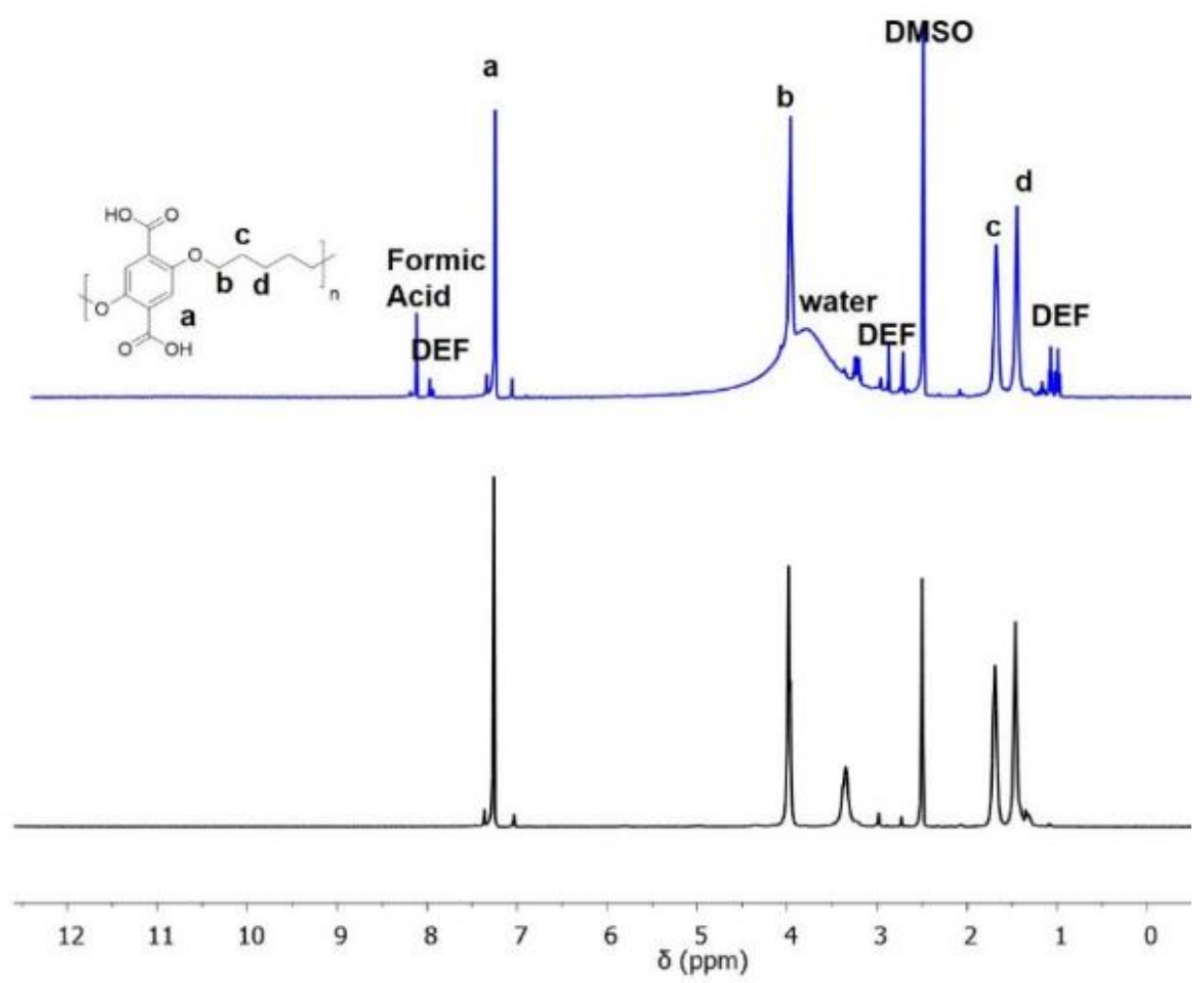

Figure S11. ${ }^{1} \mathrm{H}$ NMR of digested polyUiO-66-6a (top) and the polymer ligand pbdc-6a (bottom). 

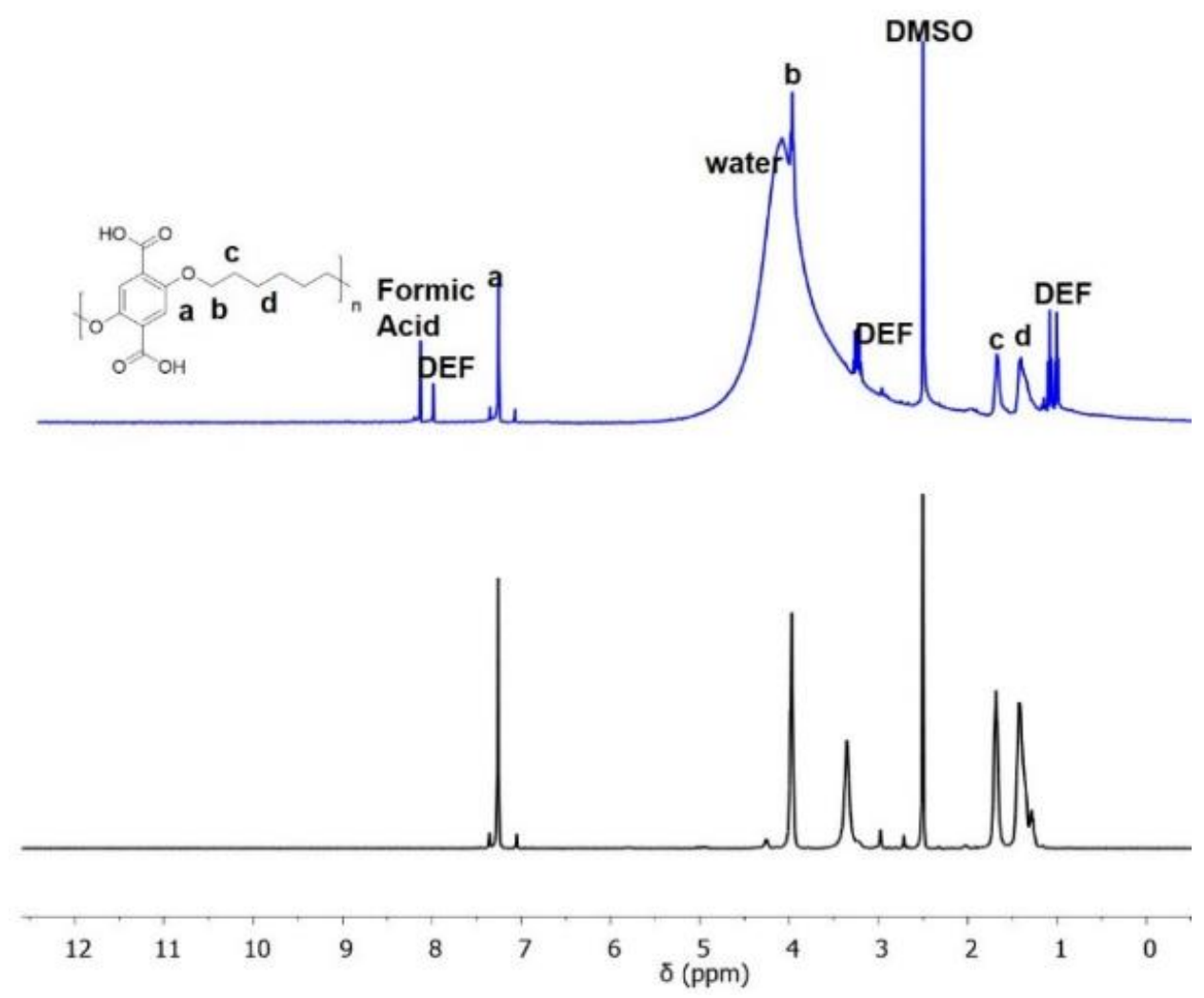

Figure S12. ${ }^{1} \mathrm{H}$ NMR of digested polyUiO-66-7a (top) and the polymer ligand pbdc-7a (bottom). 

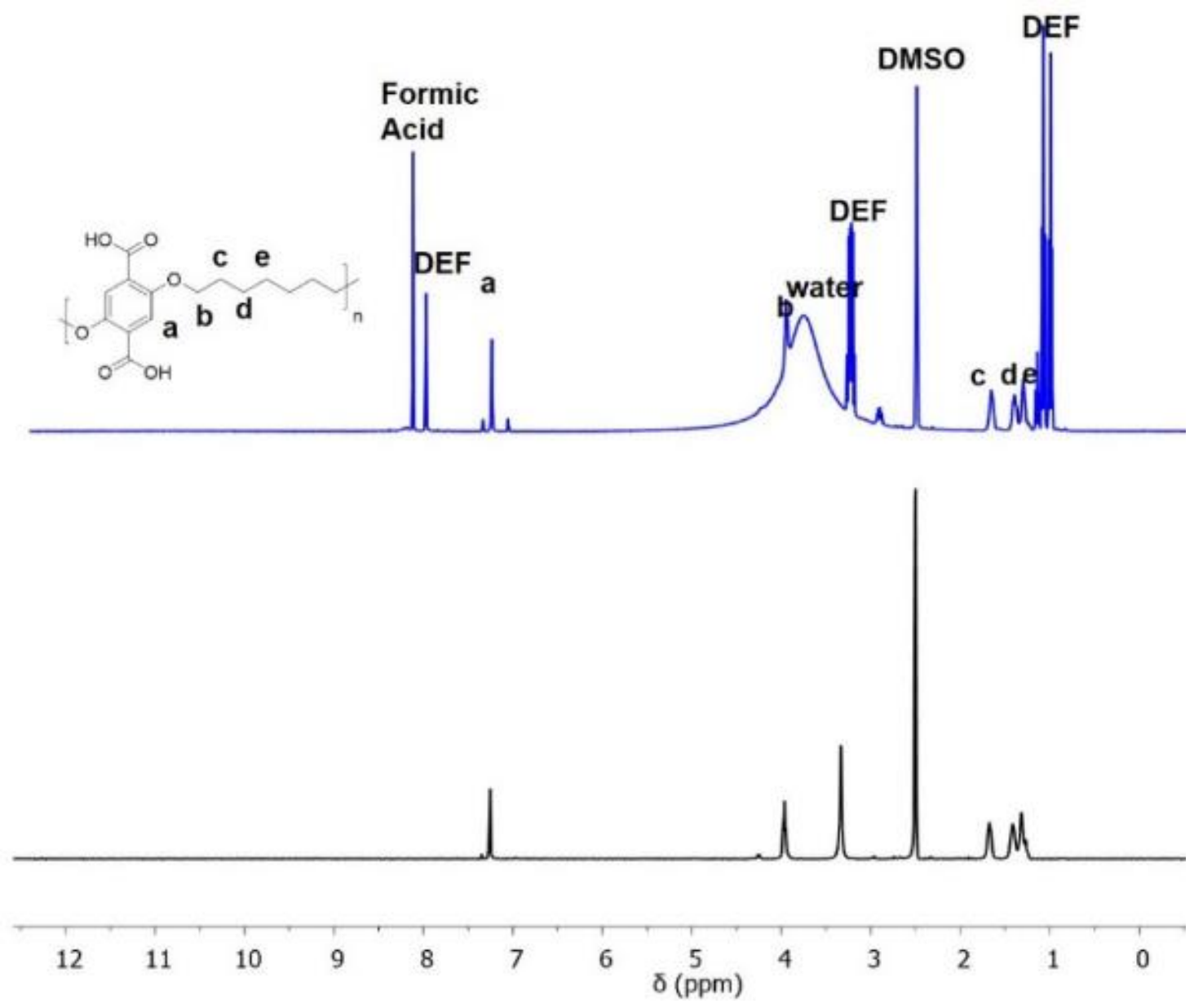

Figure S13. ${ }^{1} \mathrm{H}$ NMR of digested polyUiO-66-8a (top) and the polymer ligand pbdc-8a (bottom). 

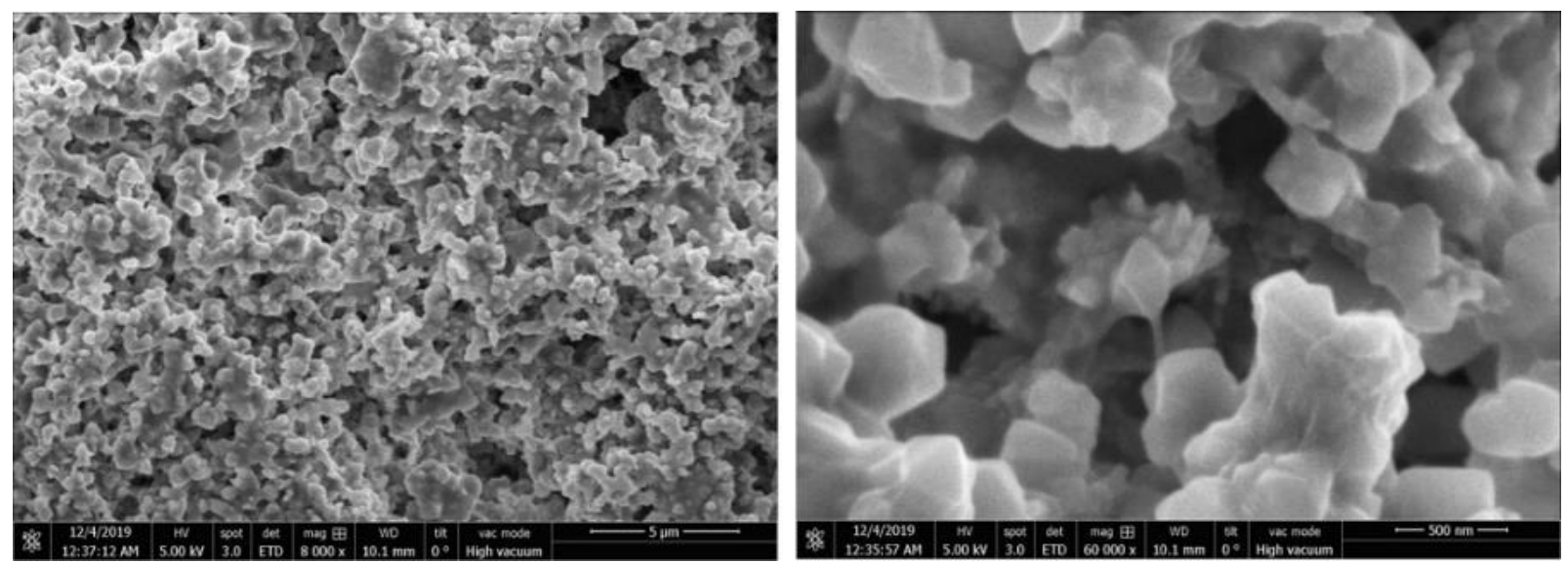

Figure S14. SEM of polyUiO-66-6a. Scale bars: $5 \boldsymbol{\mu m}$ (left) and $500 \mathrm{~nm}$ (right).
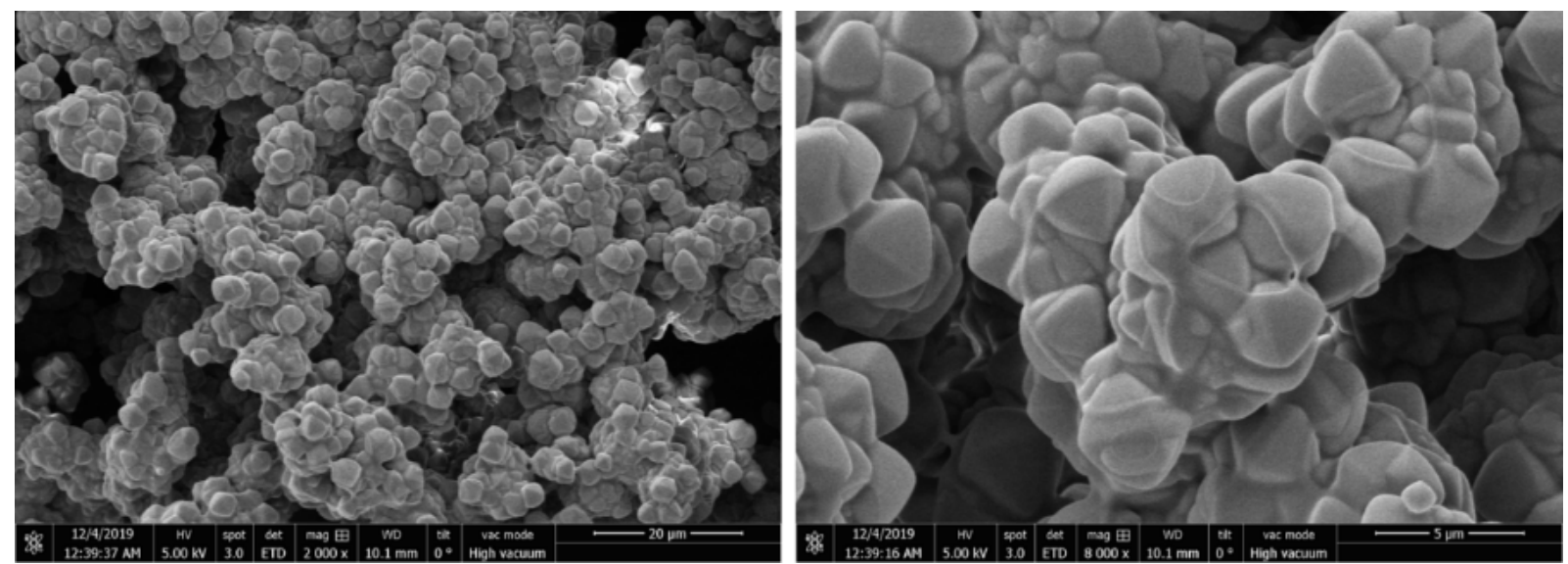

Figure S15. SEM of polyUiO-66-7a. Scale bars: $20 \mu \mathrm{m}$ (left) and $\mathbf{5} \boldsymbol{\mu m}$ (right).
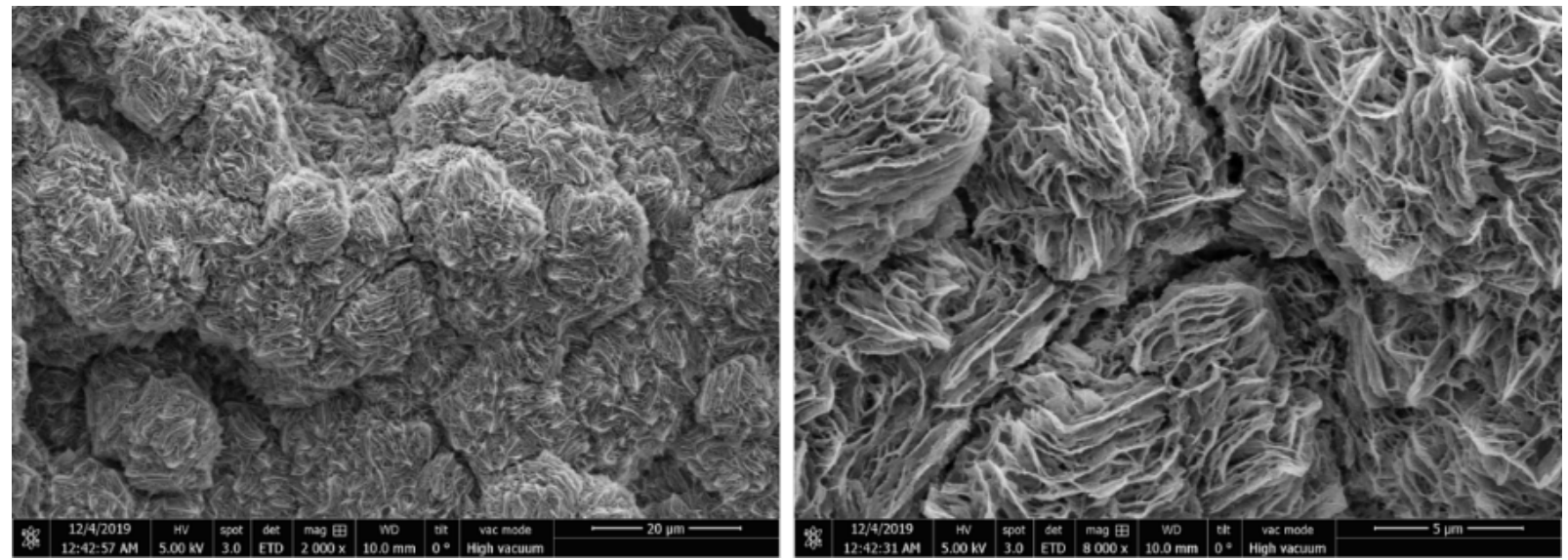

Figure S16. SEM of polyUiO-66-8a. Scale bars: $20 \mu \mathrm{m}$ (left) and $\mathbf{5} \boldsymbol{\mu m}$ (right). 


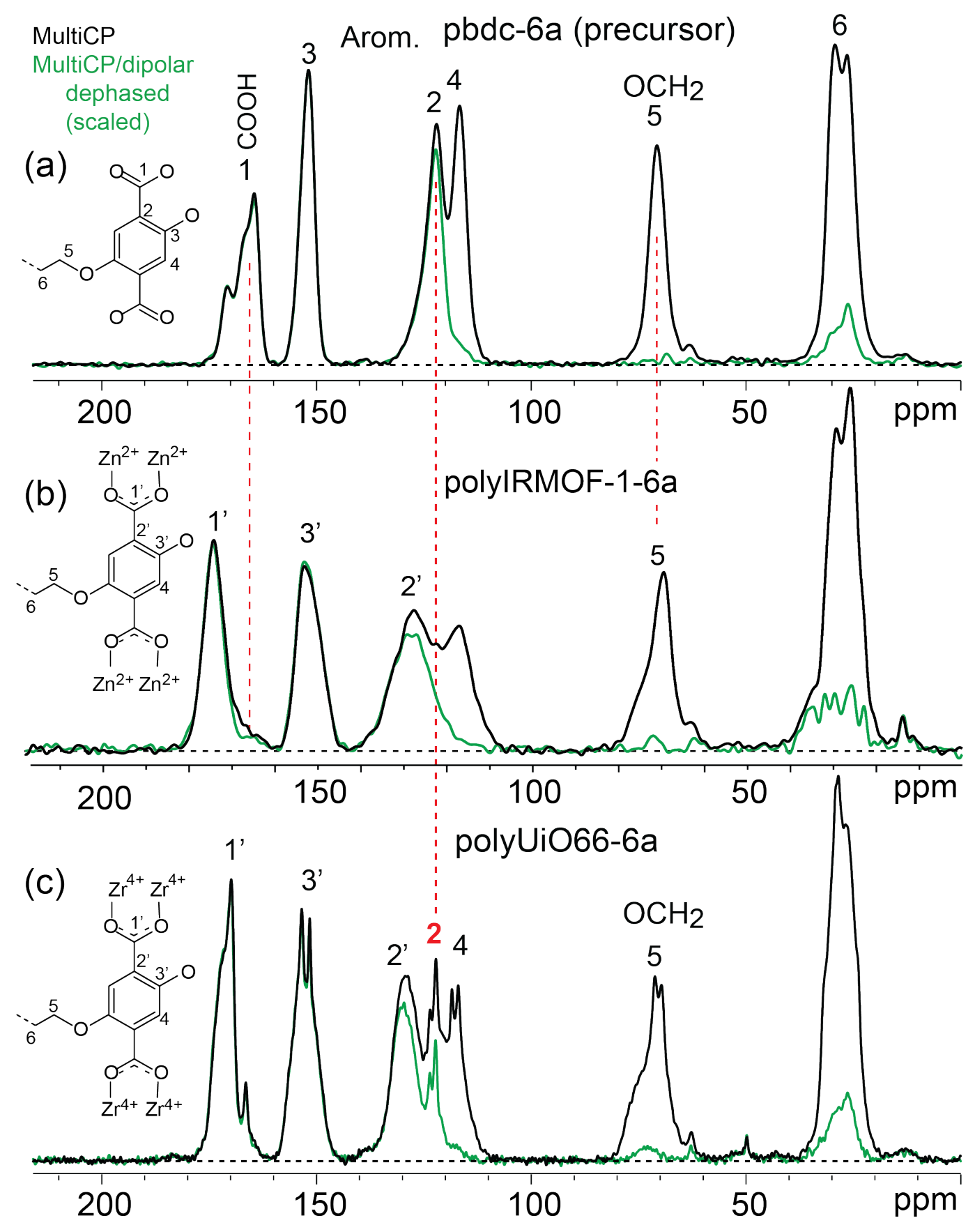

Figure S17. Probing for uncoordinated linkers in polyMOFs with $\left(\mathrm{CH}_{2}\right)_{6}$ backbone spacer segments by multiCP ${ }^{13} \mathrm{C}$ NMR: Spectra of (a) pbdc-6a, (b) polyIRMOF-1-6a, and (c) polyUiO-66-6a. Thin green lines: spectra of $\mathrm{C}$ not bonded to $\mathrm{H}$ or mobile segments, obtained after recoupled dipolar dephasing. Sharp residual signals of uncoordinated linkers, accounting for $20 \pm 6 \%$ of all linkers, are observed in (c). Small signals near 62 and $15 \mathrm{ppm}$ are assigned to residual ester-linked protecting groups. 


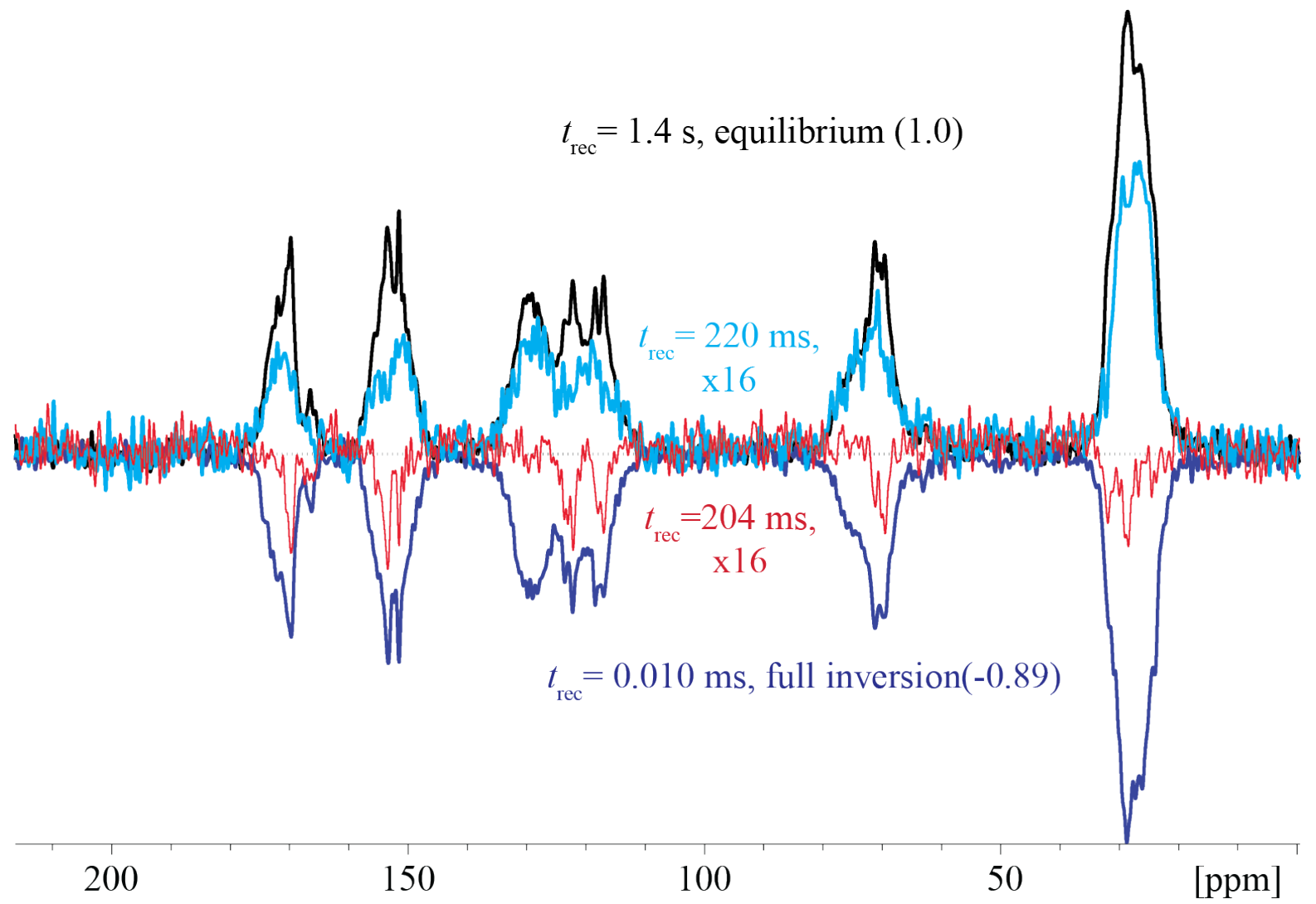

Figure S18. ${ }^{13} \mathrm{C}$-detected ${ }^{1} \mathrm{H}$ inversion recovery, for four recovery times as indicated. The sharp peaks have their own distinct ${ }^{1} \mathrm{H}$ relaxation time, which means that they are not in ${ }^{1} \mathrm{H}$ spin diffusion contact with the polyMOF, and thus must be a separate component on the $\geq 5 \mathrm{~nm}$ scale. 

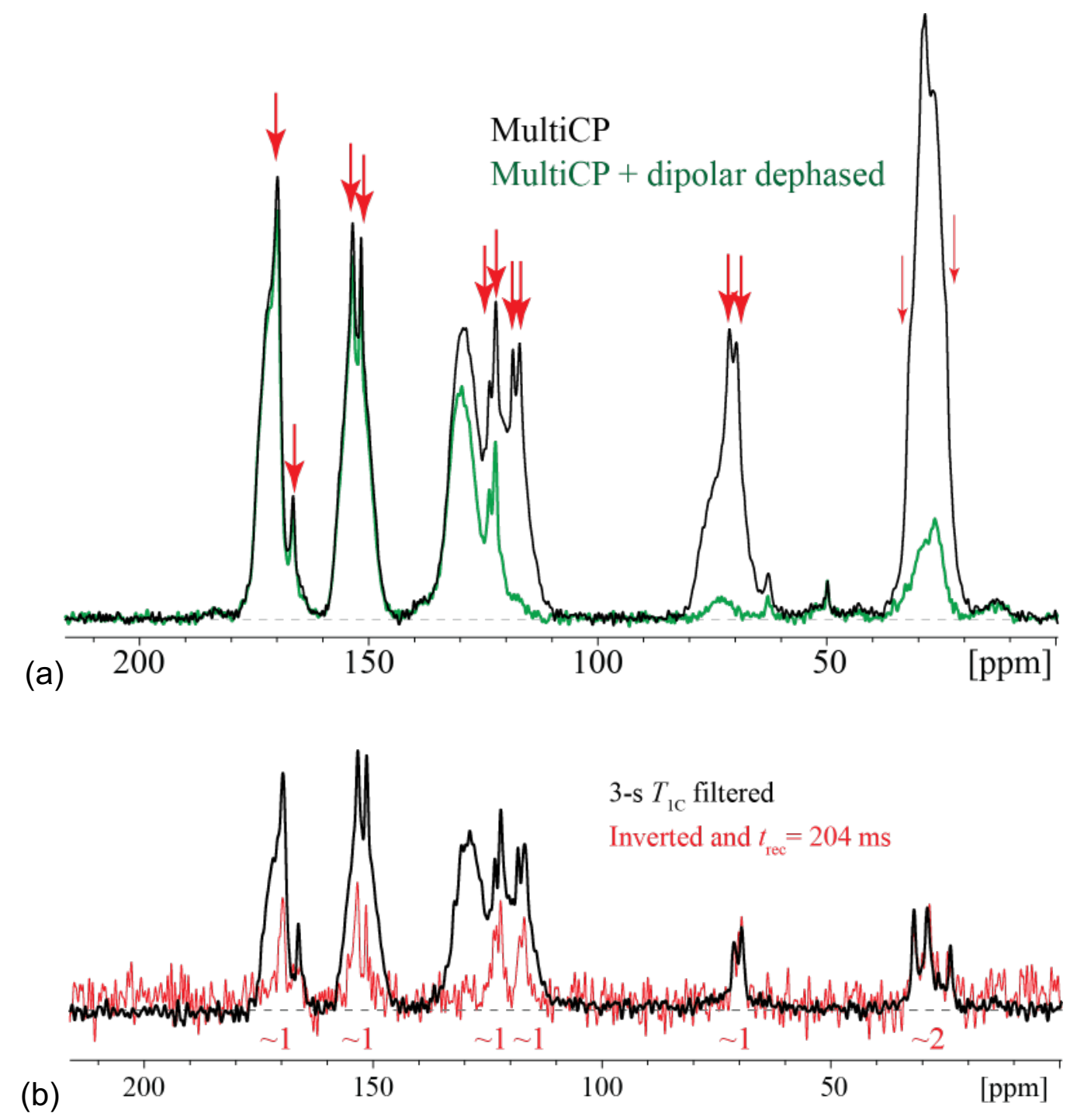

Figure S19. Relaxation analysis of the sharp ${ }^{13} \mathrm{C}$ NMR peaks in polyUiO-66-6a. (a) Sharp signals in the nearly quantitative multiCP spectrum (top black line) and the dipolar dephased multiCP spectrum (lower green line) highlighted by arrows. (b) Selection based on long relaxation times, $T_{1 \mathrm{H}}$ (thin red trace) and $T_{1 \mathrm{C}}$ (thick black line; only for $\mathrm{CH}_{2}$ groups at $<100 \mathrm{ppm}$ ). This indicates that the sharp peaks do not have liquid-like mobility, but are rigid and ordered. Within the experimental uncertainty, the relative intensities of the sharp peaks match the carbon ratio in pbdc-6a, which indicates that they are not from chemical-bonding defects. They could form an ordered layer on the surface of the polyMOF crystals, which are small according to PXRD and SEM data shown above. 


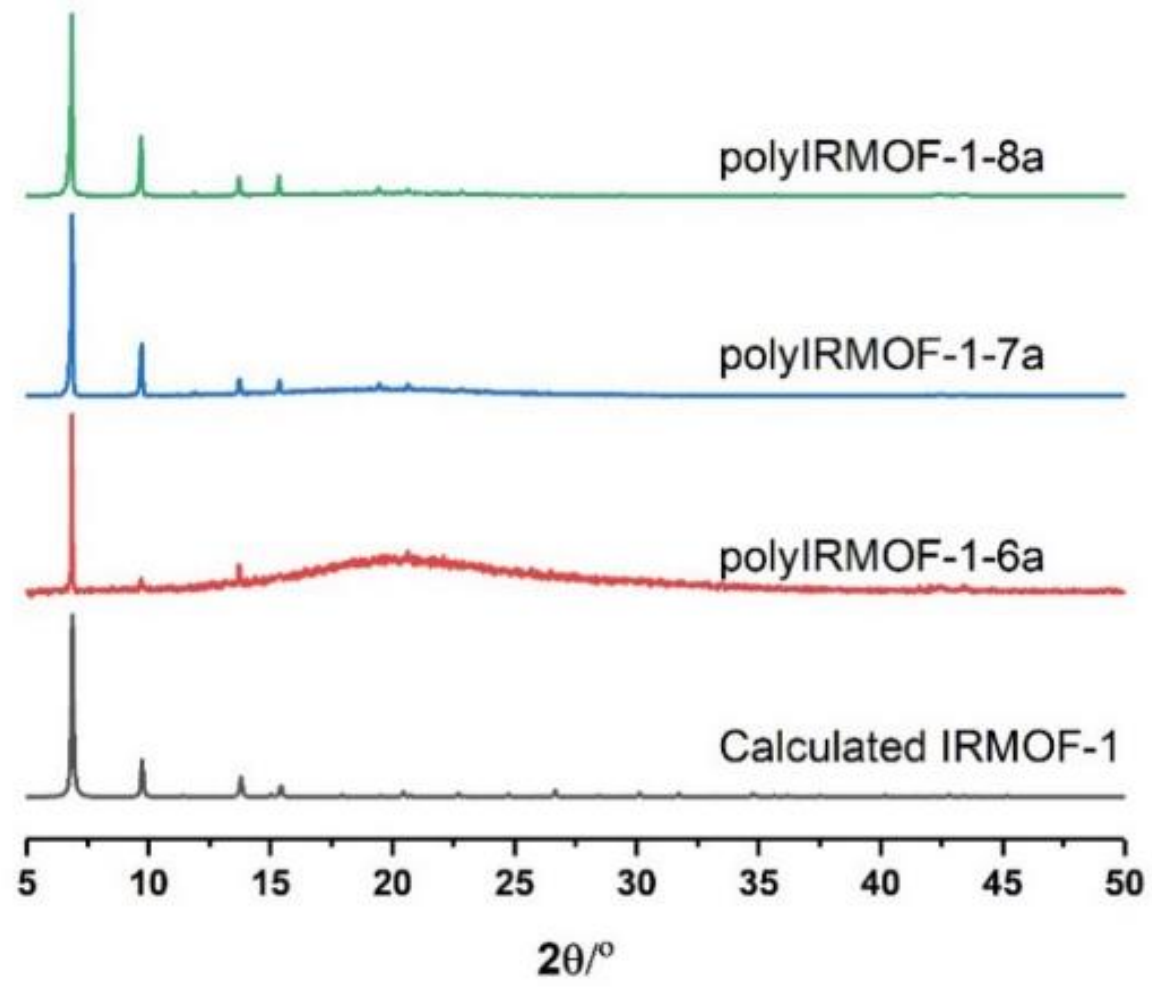

Figure S20. PXRD data obtained for polyIRMOF-1-xa prepared from pbdc-xa ligands. 

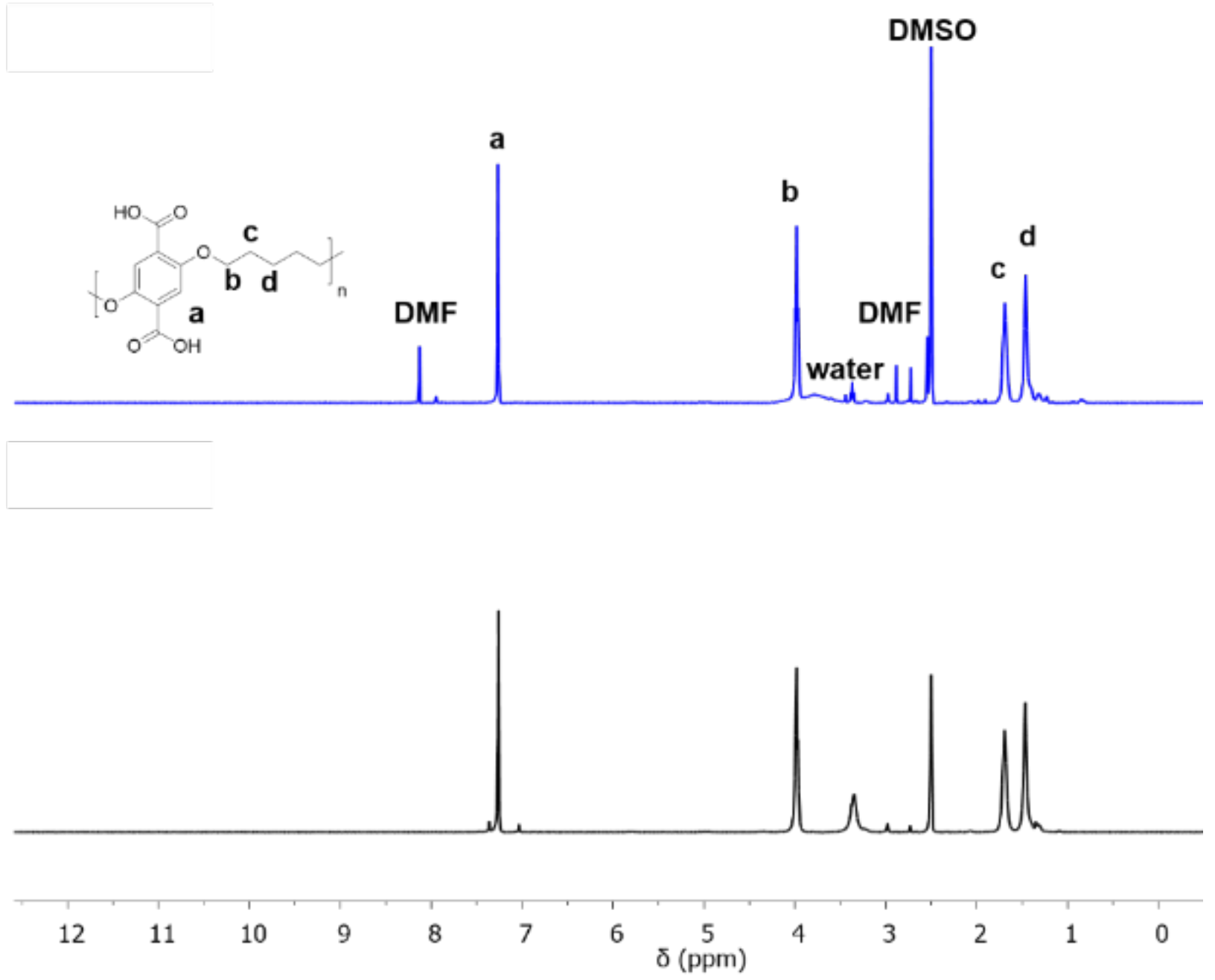

Figure S21. ${ }^{1} \mathrm{H}$ NMR of digested polyIRMOF-1-6a (top) and the polymer ligand pbdc-6a (bottom). 

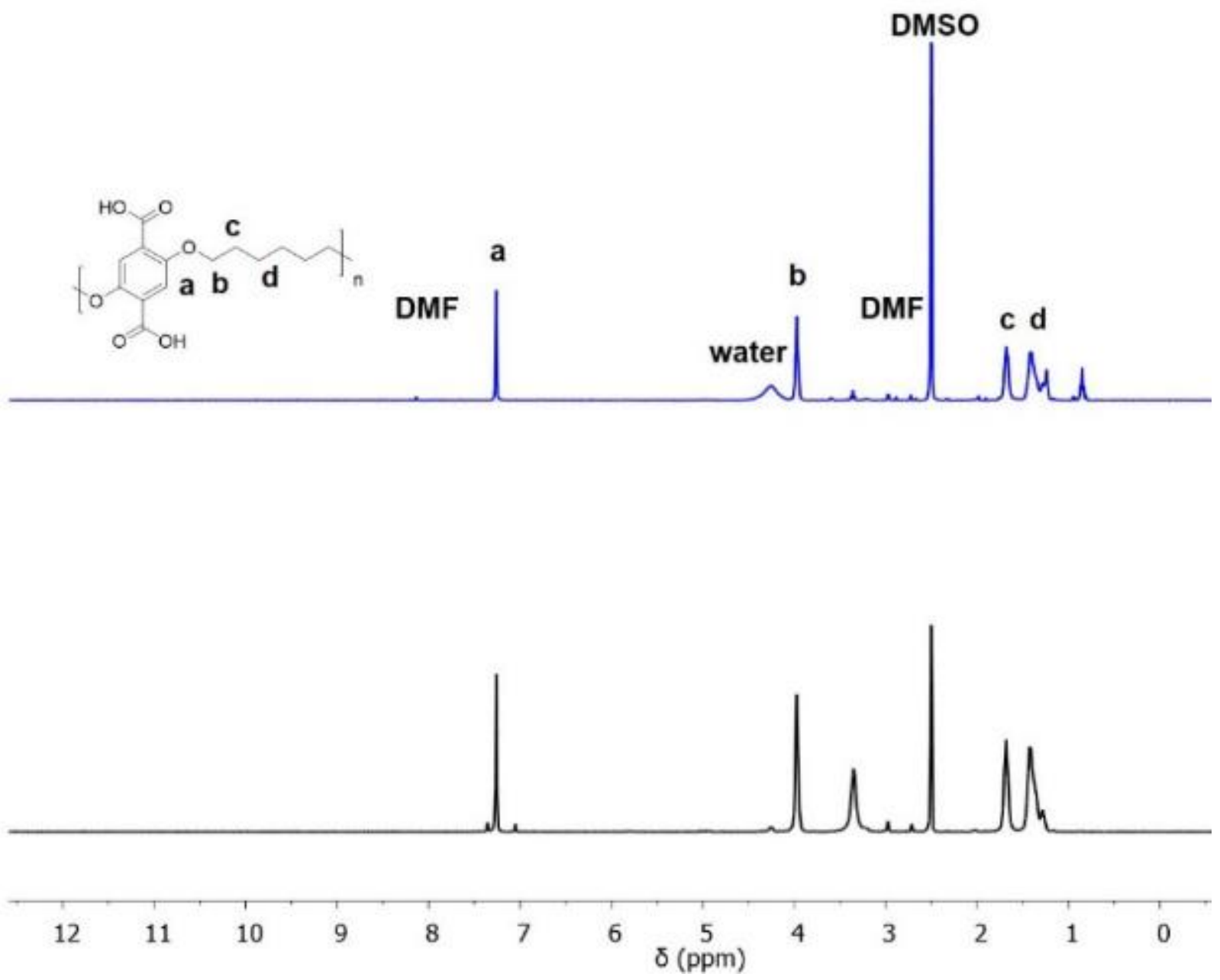

Figure S22. ${ }^{1} \mathrm{H}$ NMR of digested polyIRMOF-1-7a (top) and the polymer ligand pbdc-7a (bottom). 

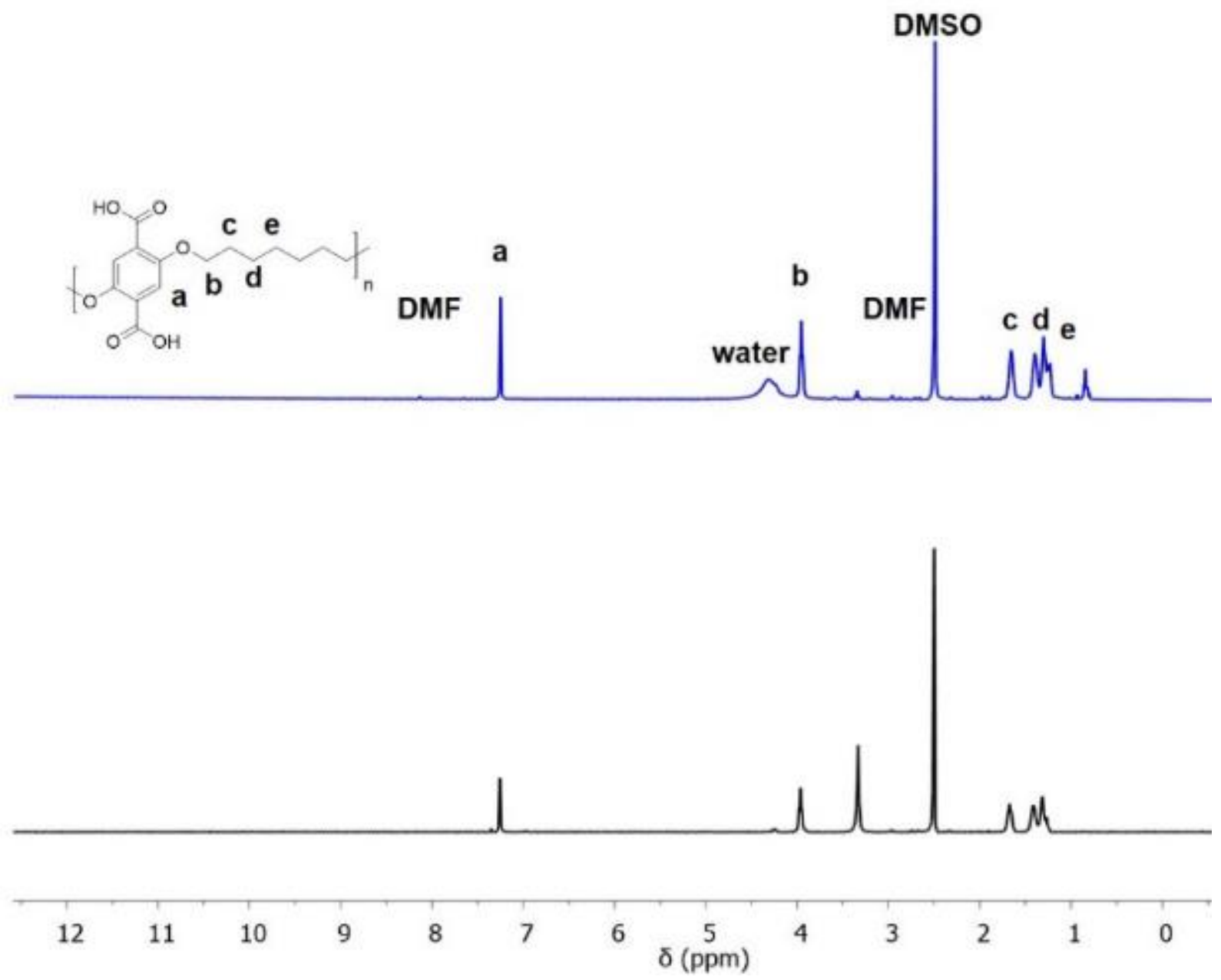

Figure S23. ${ }^{1} \mathrm{H}$ NMR of digested polyIRMOF-1-8a (top) and the polymer ligand pbdc-8a (bottom). 

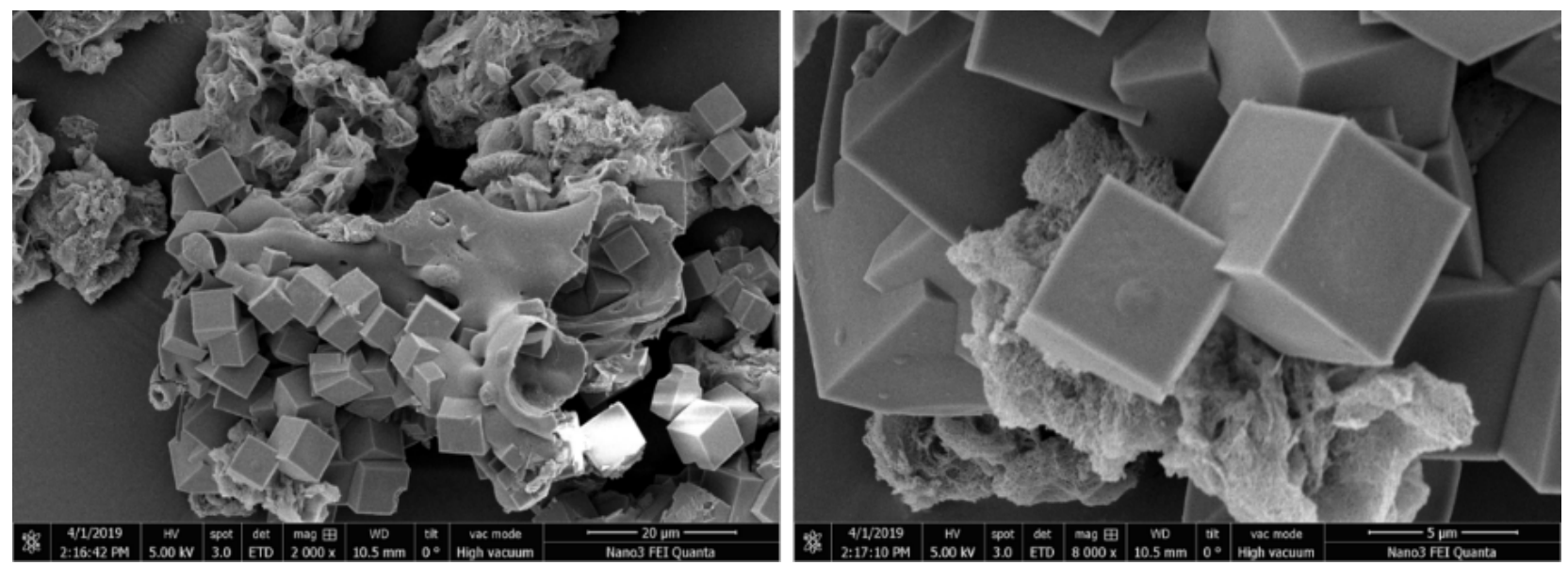

Figure S24. SEM of polyIRMOF-1-6a. Scale bars: $20 \mu \mathrm{m}$ (left) and $5 \mu \mathrm{m}$ (right).
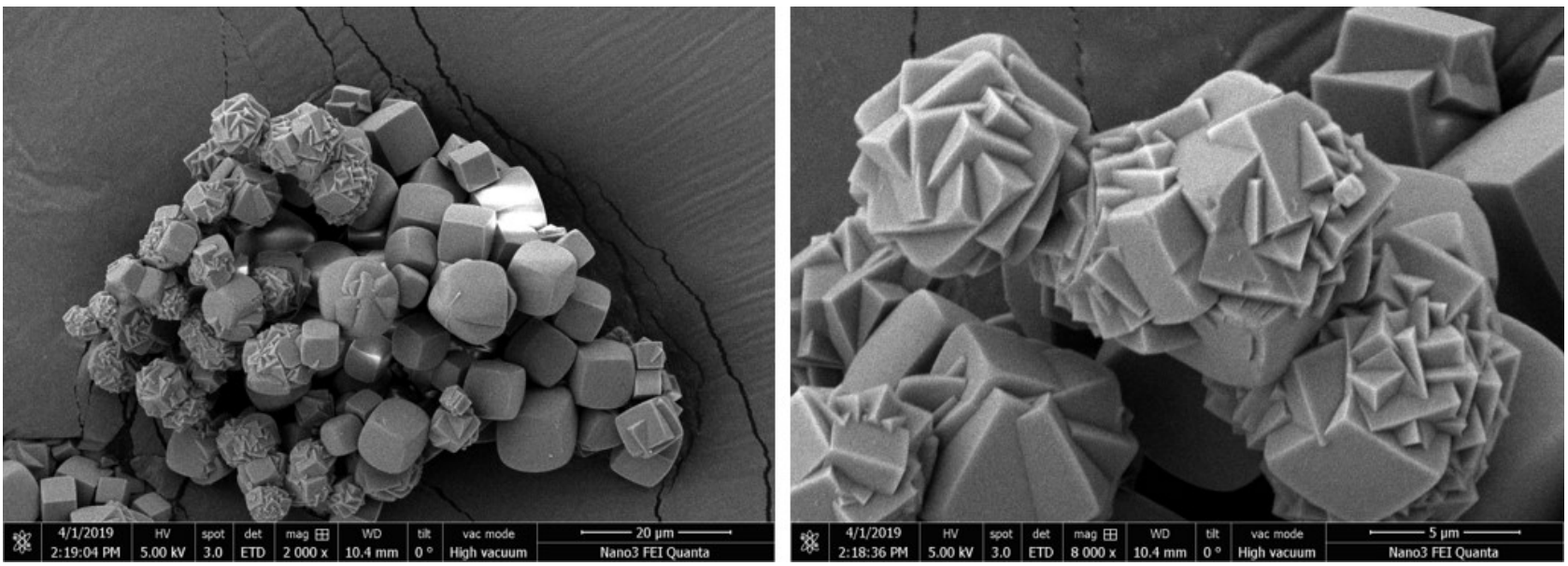

Figure S25. SEM of polyIRMOF-1-7a. Scale bars: $20 \mu \mathrm{m}$ (left) and $5 \mu \mathrm{m}$ (right).
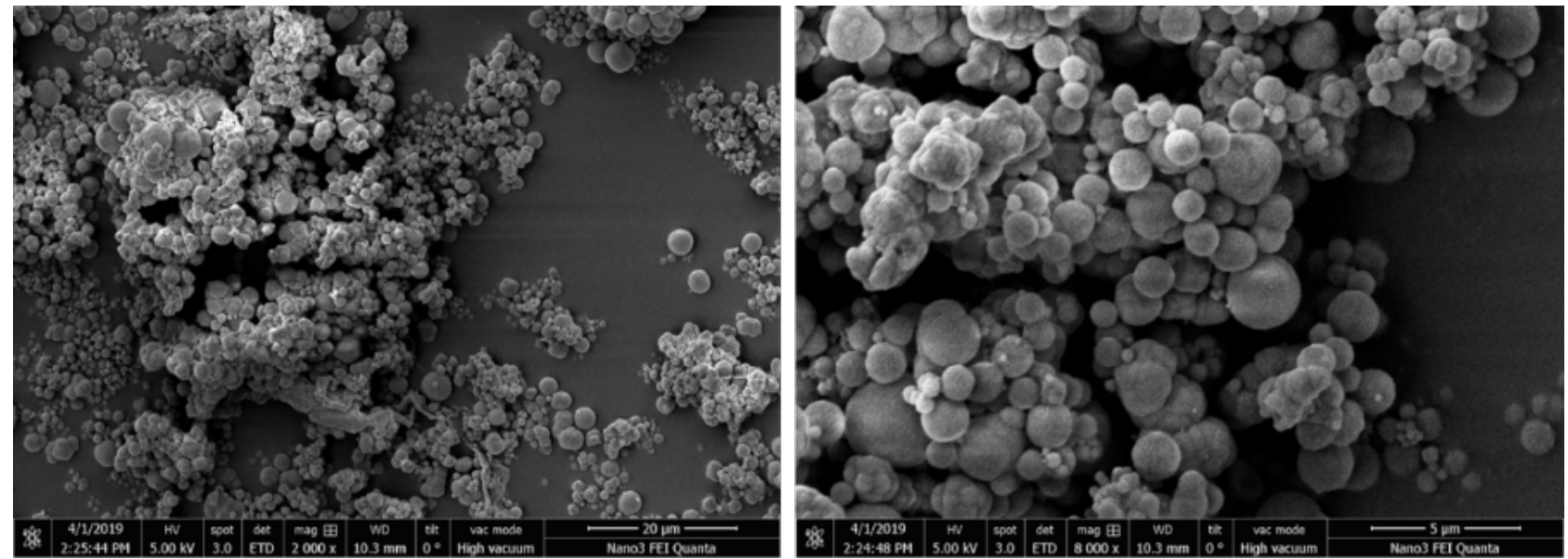

Figure S26. SEM of polyIRMOF-1-8a. Scale bars: $20 \mu \mathrm{m}$ (left) and $5 \mu \mathrm{m}$ (right). 


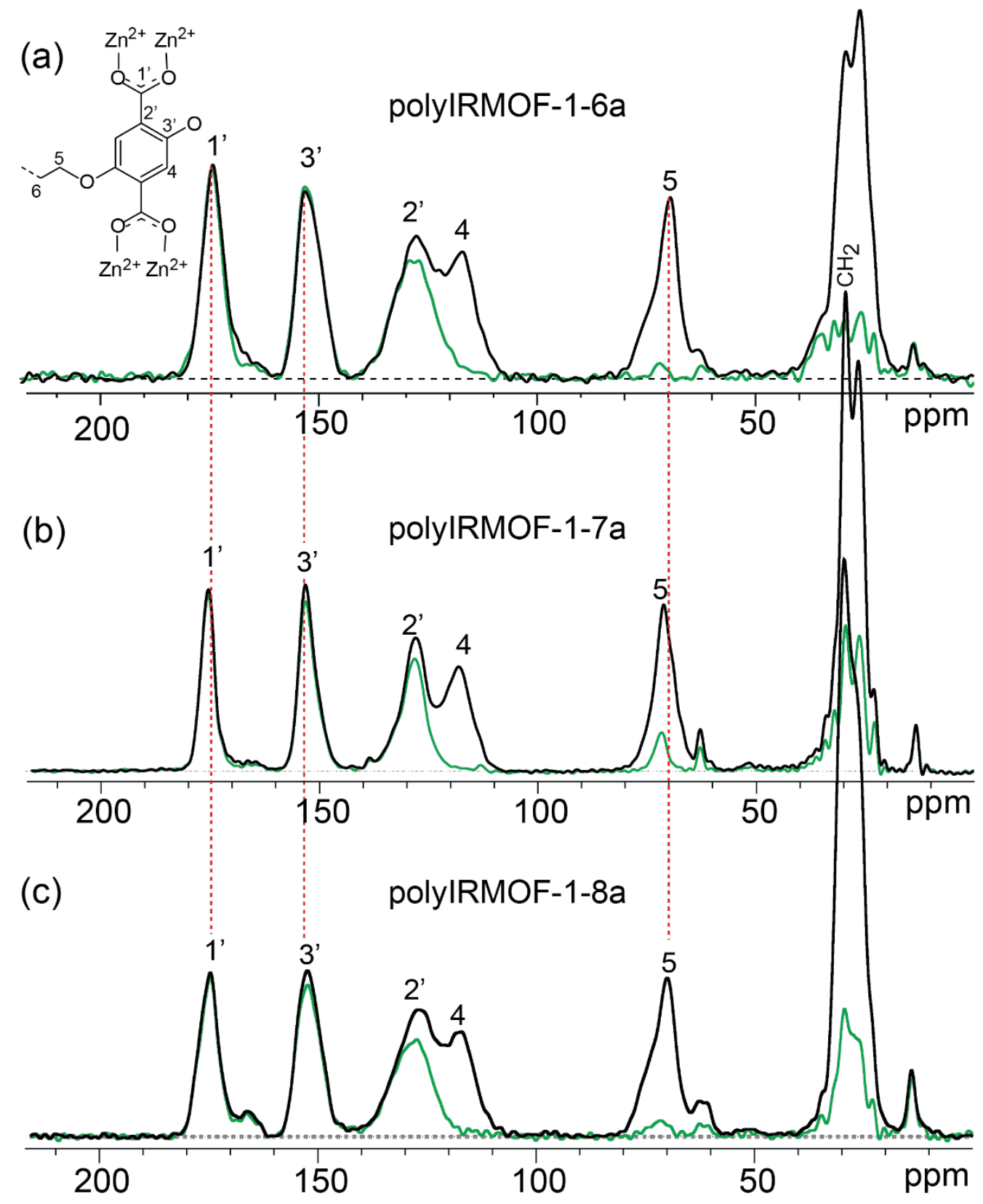

Figure S27. Nearly quantitative multiCP ${ }^{13} \mathrm{C}$ NMR spectra of polyIRMOF-1-xa with (a) $\mathrm{x}$ $=6$, (b) $x=7$, and (c) $x=8$. Thin green lines: spectra of $\mathrm{C}$ not bonded to $\mathrm{H}$ or mobile segments, obtained after recoupled dipolar dephasing. Small signals near 62 and 15 ppm are assigned to residual ester-linked protecting groups. 

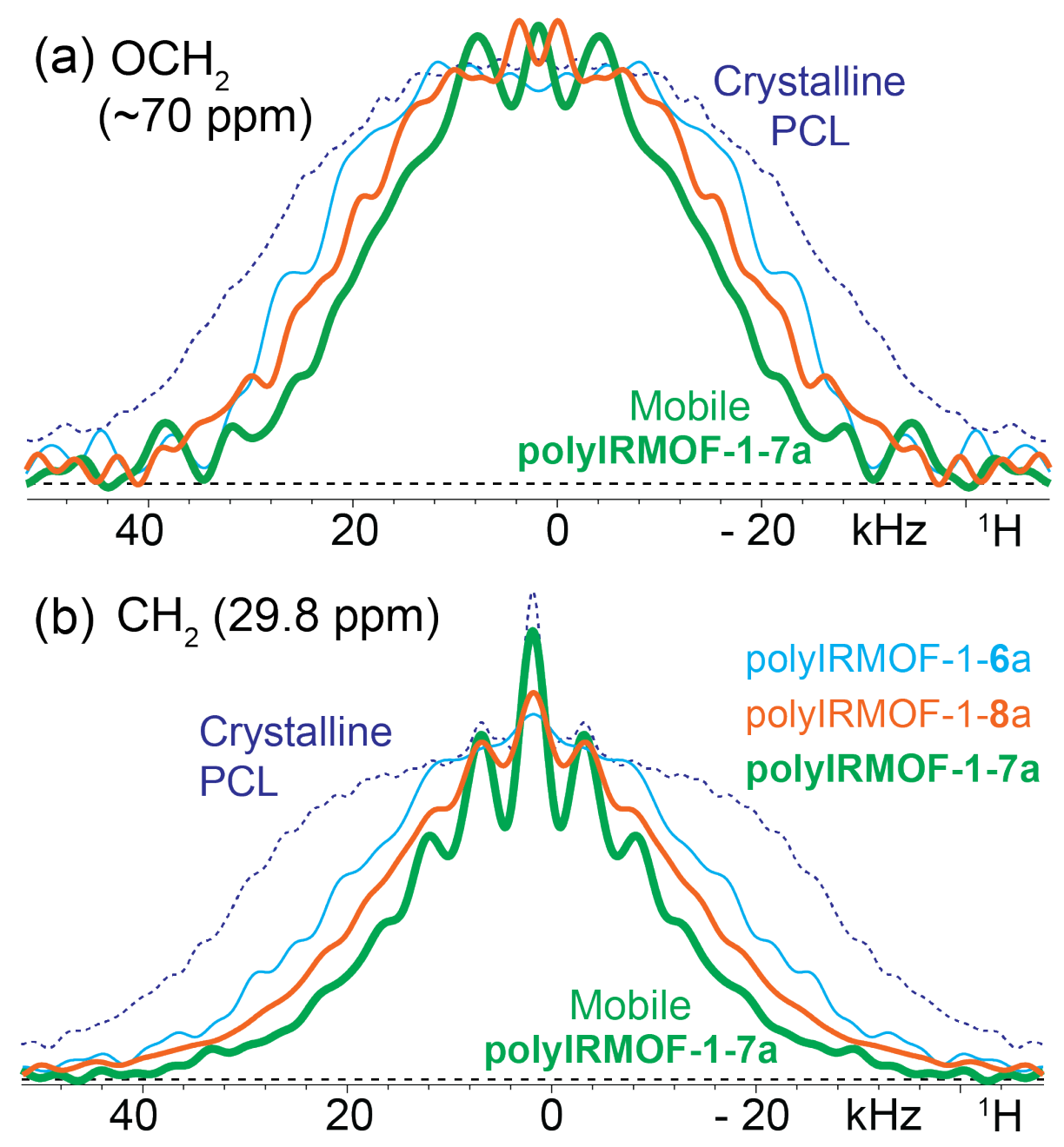

Figure S28. Probing $\mathrm{CH}_{2}$ motions in polyIRMOF-1-xa with $\mathrm{x}=6$ (thin line), 7 (thick line), and 8 (thickest line) in terms of ${ }^{1} \mathrm{H}$ wideline spectra of (a) $\mathrm{OCH}_{2}$ and (b) other $\mathrm{CH}_{2}$ groups obtained as slices at peak maxima near 70 and $29.8 \mathrm{ppm}$, respectively, from 2D WISE ${ }^{1} \mathrm{H}-{ }^{13} \mathrm{C}$ spectra. Dashed lines: Crystalline poly( $\varepsilon$-caprolactone), a polyester containing $\mathrm{O}(-\mathrm{CH} 2-) 5$ units, shown as the rigid-limit reference. A smaller line width and the appearance of spinning sidebands can be attributed to large-amplitude motions of the $\mathrm{H}$ $\mathrm{H}$ internuclear vector. Compare also to Figure 5. 

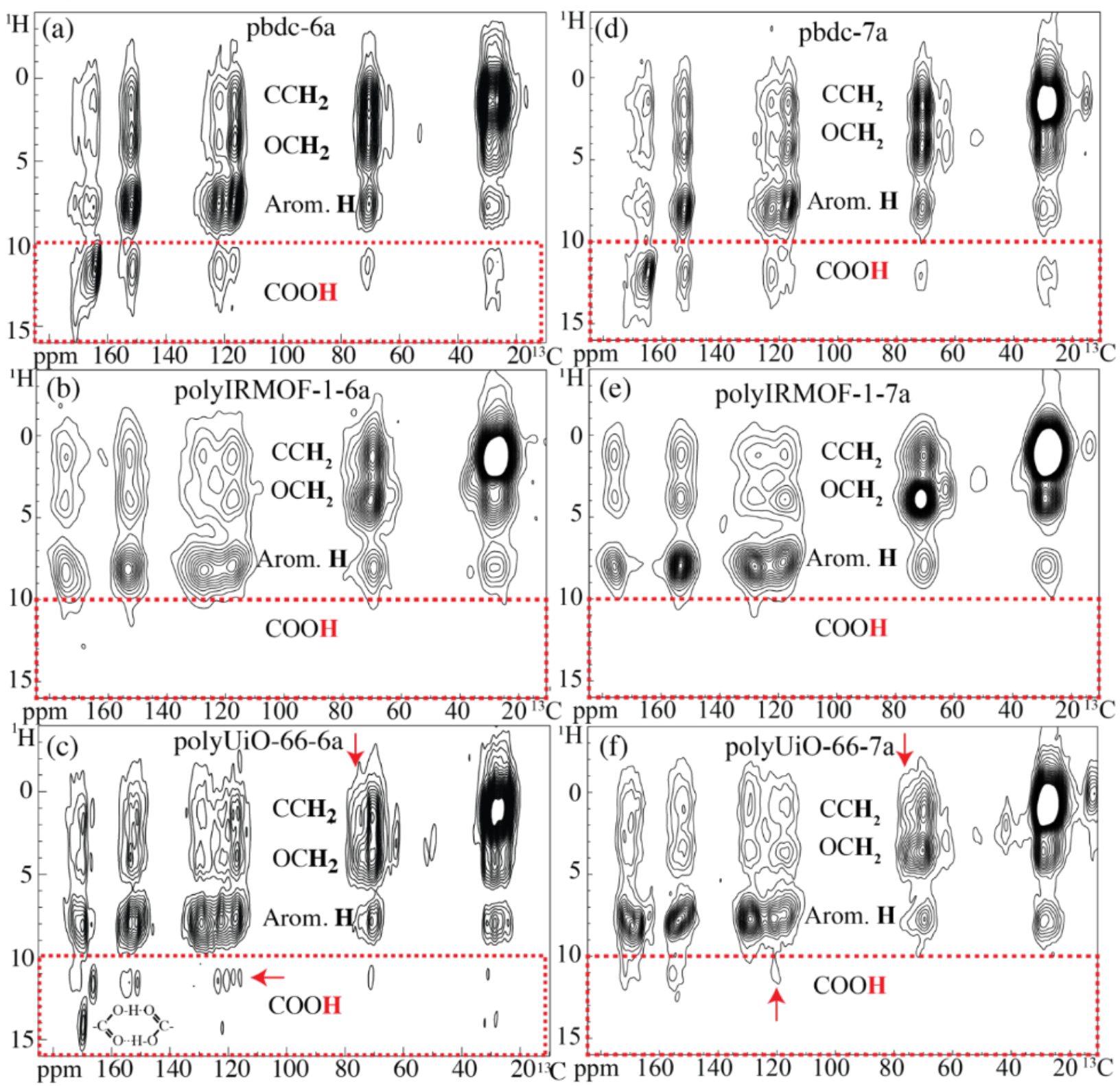

Figure S29. Two-dimensional ${ }^{1} \mathrm{H}-{ }^{13} \mathrm{C}$ HetCor NMR spectra with $0.4 \mathrm{~ms}$ of cross polarization of (a) pbdc-6a, (b) polyIRMOF-1-6a, (c) polyUiO-66-6a, (d) pbdc-7a, (e) polyIRMOF-1-7a, and (f) polyUiO-66-7a. $\mathrm{COOH}$ signals of uncoordinated linkers at $>10$ ppm are marked. None are observed for polyIRMOF-1 materials. Interestingly, the sharp ${ }^{1} \mathrm{H}$ NMR signal at $14 \mathrm{ppm}$ can be assigned to $\mathrm{H}$-bonded symmetric $\mathrm{COOH}-\mathrm{HOOC}$ dimers. The horizontal arrow in (c) points at cross peaks that show that the sharp signals in the ${ }^{13} \mathrm{C}$ spectrum of polyUiO-66-6a arise from carbons near $\mathrm{COOH}$ groups, i.e. uncoordinated linkers. 
$\mathrm{OCH}_{2}$ cross-sections from HetCor spectra

(a)

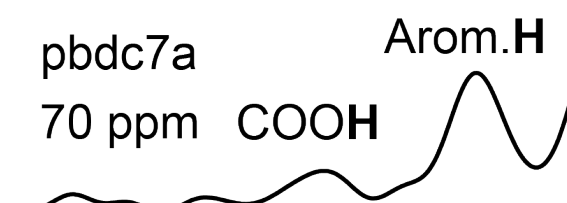

$\mathrm{OCH}_{2}{ }^{\mathrm{CCH}_{2}}$

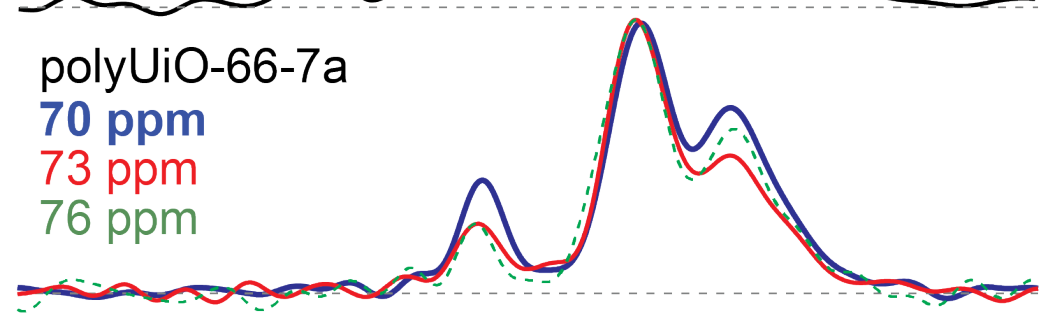

(c)

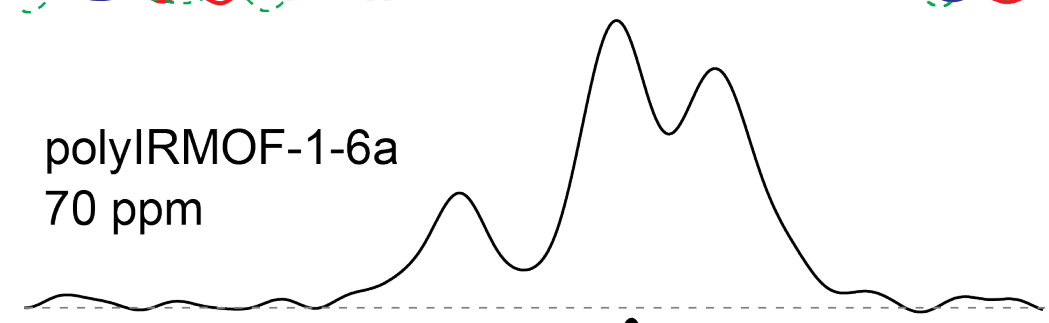

(d)

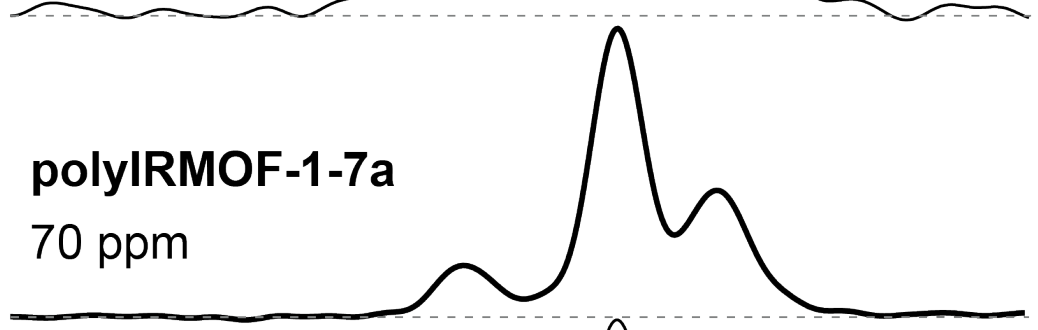

(e)

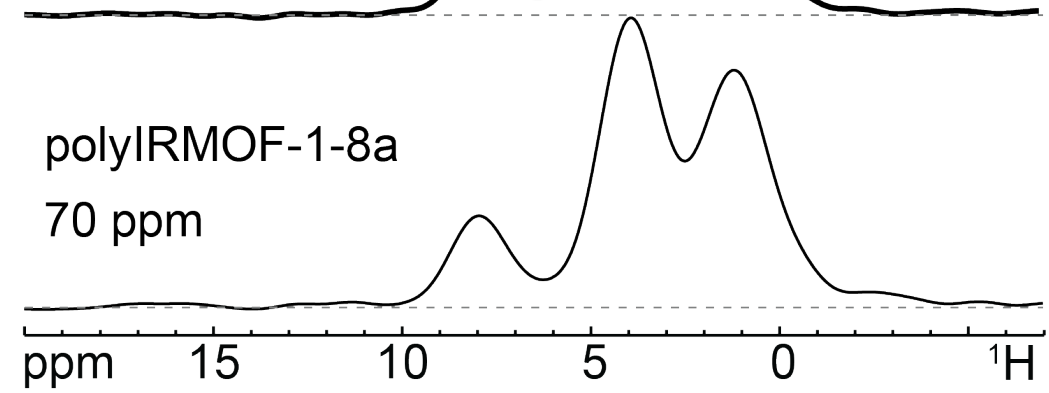

Figure S30. Vertical cross sections from two-dimensional ${ }^{1} \mathrm{H}-{ }^{13} \mathrm{C}$ HetCor NMR spectra at $\mathrm{OCH}_{2}{ }^{13} \mathrm{C}$ signal positions as indicated (in ppm). (a) pbdc-7a, (b) polyUiO-66-7a, (c) polyIRMOF-1-6a, (d) polyIRMOF-1-7a, and (e) polyIRMOF-1-8a. The line shape of polyIRMOF-1-7a in d) can be explained in terms of segmental motions weakening longrange couplings and favoring one-bond magnetization transfer in the $\mathrm{OCH}_{2}$ group. The $\mathrm{COOH}$ peak is absent from the polyMOF spectra because MOF formation deprotonates the $\mathrm{COOH}$ groups. 


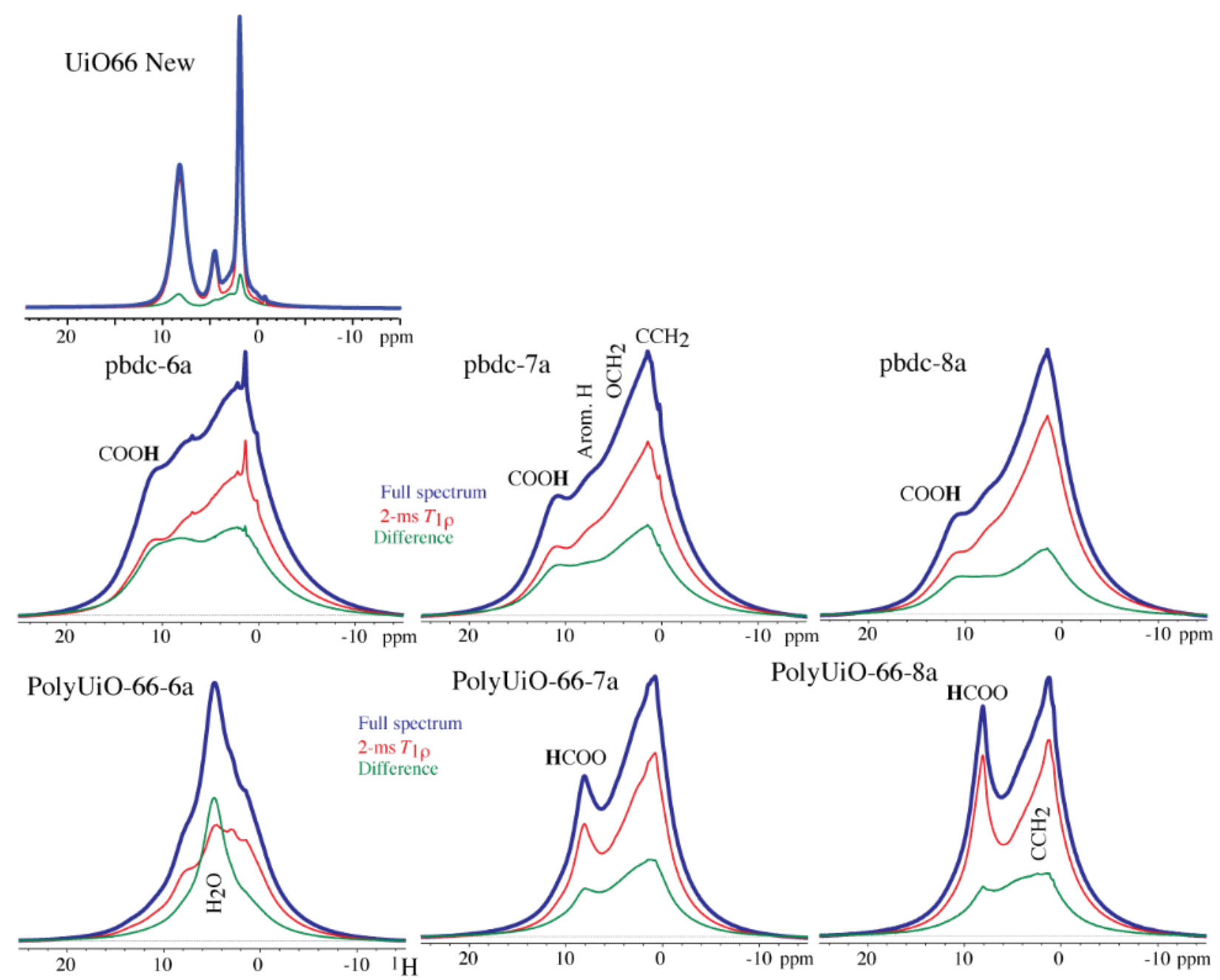

Figure S31. ${ }^{1} \mathrm{H}$ NMR spectra, recorded at $14 \mathrm{kHz}$ MAS without (thick line, top) and with 2-ms $T_{1 \mathrm{r}}$ filtering (thin green line), of pbdc-xa precursors and polyUiO-66-xa for $x=6,7$, and 8. The spectra indicate that polyUiO-66-6a contains weakly bound $\mathrm{H}_{2} \mathrm{O}$ and that polyUiO-66-7a and -8a contain formate, $\mathrm{HCOO}^{-}$, resonating near 9 ppm. 

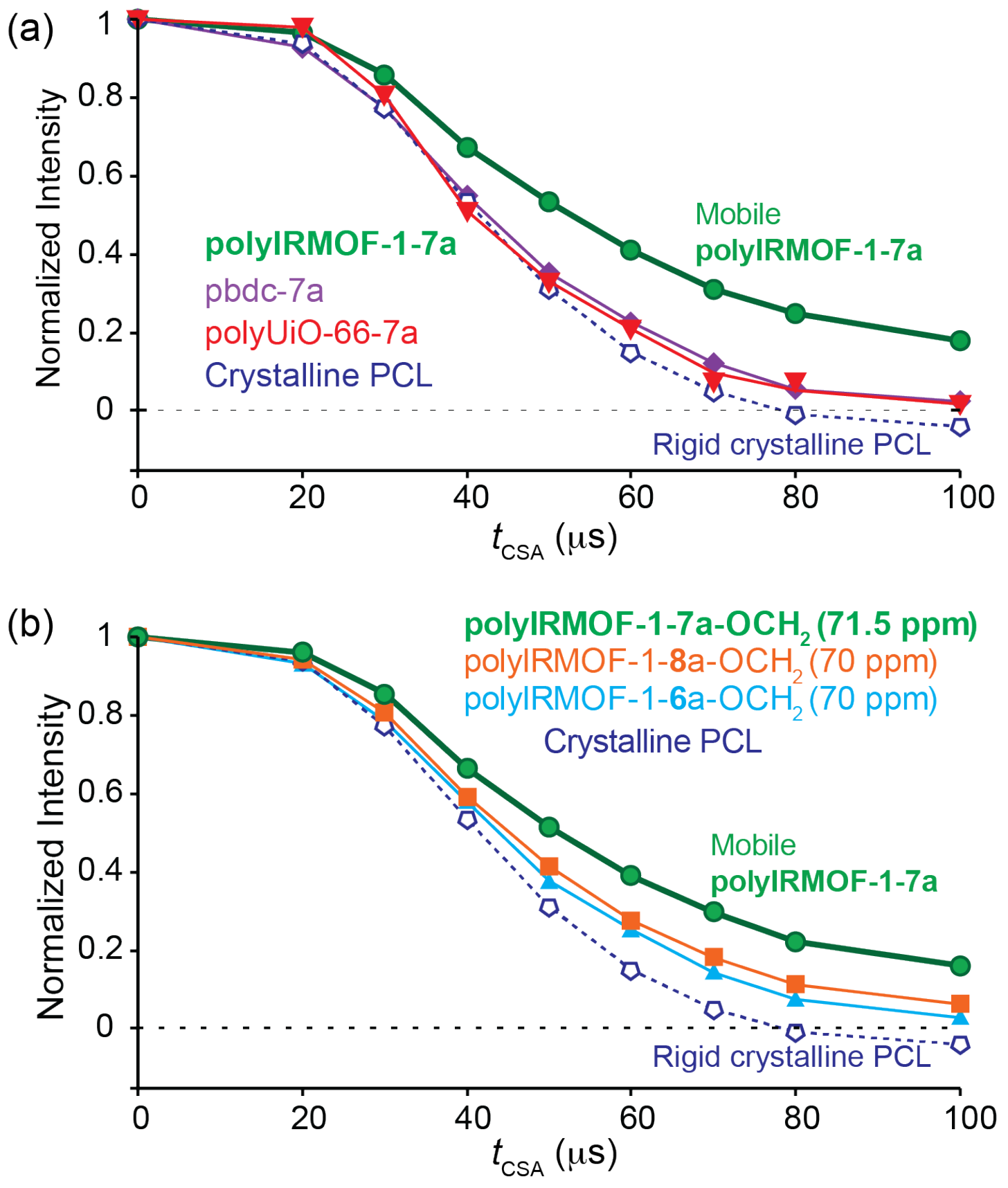

Figure S32. Probing segmental motions in polyMOFs, by ${ }^{13} \mathrm{C}$ chemical-shift anisotropy dephasing of $\mathrm{OCH}_{2}$ groups in (a) pbcd-7a, polyIRMOF-1-7a, and polyUiO-66-7a; (b) polyIRMOF-1-xa with $x=6,7$, and 8 . Data for crystalline poly(e-caprolactone), PCL, a polyester containing $\mathrm{O}\left(-\mathrm{CH}_{2}-\right)_{5}$ units, are shown as the rigid-limit reference (dashed line). Faster decay reflects a larger chemical-shift anisotropy and, for a given chemical structure, less motional averaging. This is clearly the case for polyIRMOF-1-7a. 


\section{References}

1. Hutter, J.; lannuzzi, M.; Schiffmann, F.; VandeVondele, J., cp2k: atomistic simulations of condensed matter systems. Comput. Mol. Sci. 2014, 4 (1), 15-25.

2. Weigend, F.; Ahlrichs, R., Balanced Basis Sets of Split Valence, Triple Zeta Valence and Quadruple Zeta Valence Quality for H to Rn: Design and Assessment of Accuracy. Phys. Chem. Chem. Phys. 2005, 7, 3297-3305.

3. Krack, M., Pseudopotentials for $\mathrm{H}$ to $\mathrm{Kr}$ optimized for gradient-corrected exchange-correlation functionals. Theor. Chem. Acc. 2005, 114 (1), 145-152.

4. Goedecker, S.; Teter, M.; Hutter, J., Separable dual-space Gaussian pseudopotentials. Phys. Rev. B 1996, 54 (3), 1703-1710.

5. Grimme, S.; Antony, J.; Ehrlich, S.; Krieg, H., A consistent and accurate ab initio parametrization of density functional dispersion correction (DFT-D) for the 94 elements H-Pu. J. Chem. Phys. 2010, 132 (15), 154104.

6. Bennett, A. E.; Rienstra, C. M.; Auger, M.; Lakshmi, K. V.; Griffin, R. G., Heteronuclear Decoupling in Rotating Solids. J. Chem. Phys. 1995, 103 (16), 6951-6958.

7. Hahn, E. L., Spin Echoes. Phys. Rev. 1950, 80 (4), 580-594.

8. Dixon, W. T.; Schaefer, J.; Sefcik, M. D.; Stejskal, E. O.; McKay, R. A., Total suppression of sidebands in CPMAS C-13 NMR. J. Magn. Reson. 1982, 49 (2), 341-345.

9. Fung, B. M.; Khitrin, A. K.; Ermolaev, K., An improved broadband decoupling sequence for liquid crystals and solids. J. Magn. Reson. 2000, 142 (1), 97-101.

10. Duan, P.; Schmidt-Rohr, K., Composite-pulse and partially dipolar dephased multiCP for improved quantitative solid-state (13)C NMR. J. Magn. Reson. 2017, 285, 68-78.

11. Caravatti, P.; Braunschweiler, L.; Ernst, R. R., Heteronuclear correlation spectroscopy in rotating solids. Chem. Phys. Lett. 1983, 100 (4), 305-310.

12. Bielecki, A.; Kolbert, A. C.; De Groot, H. J. M.; Griffin, R. G.; Levitt, M. H., Frequency-Switched Lee-Goldburg Sequences in Solids. In Adv. Magn. Reson., Elsevier: 1990; pp 111-124.

13. Schmidt-Rohr, K.; Clauss, J.; Spiess, H. W., Correlation of structure, mobility, and morphological information in heterogeneous polymer materials by two-dimensional widelineseparation NMR spectroscopy. Macromolecules 1992, 25 (12), 3273-3277.

14. Mao, J. D.; Schmidt-Rohr, K., Separation of aromatic-carbon 13C NMR signals from dioxygenated alkyl bands by a chemical-shift-anisotropy filter. Solid State Nucl. Magn. Reson. 2004, 26 (1), 36-45.

15. Abragam, A., The Principles of Nuclear Magnetism. Oxford University Press: 1983; p 64. 